\title{
Creep-fatigue life assessment of cruciform weldments using the linear matching method
}

\author{
Yevgen Gorash, Haofeng Chen* \\ Department of Mechanical \& Aerospace Engineering, University of Strathclyde, James Weir Building, 75 Montrose Street, Glasgow G1 1XJ, UK
}

\begin{abstract}
This paper presents a creep-fatigue life assessment of a cruciform weldment made of the steel AISI type $316 \mathrm{~N}(\mathrm{~L})$ and subjected to reversed bending and cyclic dwells at $550^{\circ} \mathrm{C}$ using the Linear Matching Method (LMM) and considering different weld zones. The design limits are estimated by the shakedown analysis using the LMM and elastic-perfectly-plastic material model. The creepfatigue analysis is implemented using the following material models: 1) Ramberg-Osgood model for plastic strains under saturated cyclic conditions; 2) power-law model in "time hardening" form for creep strains during primary creep stage. The number of cycles to failure $N^{\star}$ under creep-fatigue interaction is defined by: a) relation for cycles to fatigue failure $N^{*}$ dependent on numerical total strain range $\Delta \varepsilon_{\text {tot }}$ for the fatigue damage $\omega_{\mathrm{f}} ;$ b) long-term strength relation for the time to creep rupture $t^{*}$ dependent on numerical average stress $\bar{\sigma}$ during dwell $\Delta t$ for the creep damage $\omega_{\text {cr }}$; c) non-linear creep-fatigue interaction diagram for the total damage. Numerically estimated $N^{\star}$ for different $\Delta t$ and $\Delta \varepsilon_{\text {tot }}$ shows good quantitative agreement with experiments. A parametric study of different dwell times $\Delta t$ is used to formulate the functions for $N^{\star}$ and residual life $L^{\star}$ dependent on $\Delta t$ and normalised bending moment $\tilde{M}$, and the corresponding contour plot intended for design applications is created.
\end{abstract}

Keywords: Creep, Damage, Finite element analysis, FSRF, Low-cycle fatigue, Type 316 steel, Weldment

\section{Introduction}

Many engineering structures and components of power plants and chemical facilities are subjected to cyclic loading at high temperature. Welding is the most widely applicable method among the actual manufacturing technologies for assembling of compound structures for industrial applications. Power plant components are usually manufactured of austenitic steels, most often the stainless steel AISI type $316 \mathrm{~N}(\mathrm{~L})$. This steel is widely used in power-generating industry since early 60 s of 20th century due to good mechanical properties [1] including allowable working temperatures to over $650^{\circ} \mathrm{C}$, low cycle fatigue and creep resistivity, excellent long-term ductility to over $100 \%$ depending on temperature, etc. [1]. According to industrial experience long-term integrity of structures manufactured of austenitic steels that operate at high temperatures is usually limited by the performance of welded joints in critical locations. Thus, the assessment of the weld region, which provides a particular difficulty under variable loading and high temperature due to complex microstructure, has the priority importance for structural design and life assessments. So there is an urgent necessity to comprehensively study how the key operational parameters (such as intensity of varying applied loading and duration of dwell period) may effect the long-term strength of weldment. Based on these studies, analytical formulations depending on key operational parameters within the practical

\footnotetext{
*Corresponding author. Tel.: +44 141 5482036; Fax: +44 1415525105

Email address: haofeng. chen@strath.ac.uk (Haofeng Chen)

URL: http://www. thelmm.co.uk (Haofeng Chen)
}

range of service conditions may be produced for preliminary life assessment of welded structures during the design stage.

This paper demonstrates the recent extension of the LMM to include cyclic creep assessment [2] in application to a creepfatigue analysis of a cruciform weldment made of the stainless steel AISI type $316 \mathrm{~N}(\mathrm{~L})$. The obtained results are compared with the results of experimental studies implemented by Bretherton et al. $[3,4,5]$ with the overall objective to identify fatigue strength reduction factors (FSRF) of austenitic weldments for further design application. These studies included a series of strain-controlled tests at $550^{\circ} \mathrm{C}$ with different combinations of reversed bending moment and dwell time. Five levels of reversed bending moment histories corresponding to defined values of total strain range $\Delta \varepsilon_{\text {tot }}$ in remote parent material ( $1 \%$, $0.6 \%, 0.4 \%, 0.3 \%, 0.25 \%$ ) were used in combination with three variants of creep-fatigue conditions: pure fatigue, 1 hour and 5 hours of dwell period of hold in tension.

Previous modelling studies devoted to analysis and simulation of these experiments $[3,4,5]$ include the following works. Bretherton and Budden $[4,6]$ carried out the simplified crack initiation assessments using the R5 Procedure and more accurate cyclic elastic-plastic-creep Finite Element Analysis (FEA) using a state variable constitutive model, resulting in rather conservative estimation of the specimen endurances. Ainsworth et al. [7, 8] applied the revised R5 creep-fatigue crack initiation procedure (updated with new guidelines and analysis features for austenitic weldments), which resulted in less conservative life estimations comparing to the prediction results obtained by the French $\sigma_{\mathrm{d}}$ method. Bate et al. [9] investigated improvements to the R5 Volume 2/3 Appendix A4 Procedures for the as- 
sessment of the fatigue and creep-fatigue life of austenitic weldments taking into account geometric effects in as-welded and dressed weld types, resulting in even less conservative estimation of the specimen endurances. Finally, Ponter and Chen [10] applied the Linear Matching Method (LMM) for the description of elastic, plastic and creep material behaviour to the numerical assessments using the R5 standard creep/fatigue model according to the methodology of the life assessment Procedure R5 [11]. Those results [10] are good, except that the reduction in fatigue life is underestimated, thus, providing the minimum relative conservatism among the available modelling studies.

Comprehensive modelling of structural features with complex microstructure and material behaviour such as weldments under high-temperature and cyclic loading conditions can be achieved by using of FEA with direct analysis methods, which calculate the stabilised steady-state response of structures with far less computational effort than full step-by-step analysis. Most practically included among these methods are the Direct Cyclic Analysis [12, 13] and the LMM framework [14, 15]. The LMM is distinguished from the other simplified methods by ensuring that both the equilibrium and compatibility are satisfied at each stage $[14,15,16,17]$. In addition to the shakedown analysis method [16], the LMM has been extended beyond the range of most other direct methods by including the evaluation of ratchet limit $[14,15,17]$ and steady-state cyclic behaviour with creep-fatigue interaction [18]. The LMM ABAQUS user subroutines [19] have been consolidated by the R5 Procedure [11] research programme of EDF Energy to the commercial standard, and are counted to be the method most amenable to practical engineering applications involving complicated thermo-mechanical load history $[15,17]$.

Recently [2] the LMM has been much improved both theoretically and numerically including more accurate predictions of the stabilised cyclic response of a structure under creep conditions, and more accurate assessments of the resulting cyclic and residual stresses, creep strain, plastic strain range, ratchet strain and the elastic follow-up factor. Those improvements are validated through application of an extended LMM [2] to a benchmark problem of a Bree cylinder [20] subjected to cyclic thermal load and constant mechanical load and confirmed by the comparison of numerical results with existing analytic solutions. In addition, the applicability of this extended LMM [2] to more general engineering problems is verified by creep-fatigue analysis and damage assessment of a holed plate subjected to cyclic thermal loads and a constant uniaxial tension.

In fact, the analyses presented in this paper revisit previous LMM assessments [10] of the same experimental studies $[3,4,5]$ using the method outlined in [2], more accurate modelling of the specimen structure and the material behaviour of its regions including LCF endurance, creep and long-term strength properties. In contrast to [10], creep damage is assessed using time fraction rule instead of ductility exhaustion, which provides over-conservatism in combination with timehardening creep law. The non-linear creep-fatigue interaction diagram instead of linear is also found to be more suitable for the assessment of critical creep-fatigue damage at fracture.

The main objective of work is to formulate a creep-fatigue

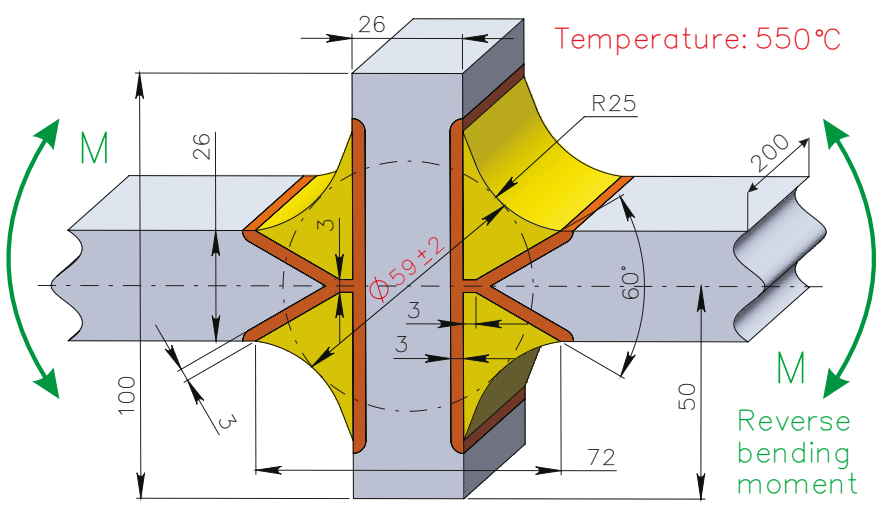

Figure 1: Dimensions of the cruciform weld specimens and applied loading

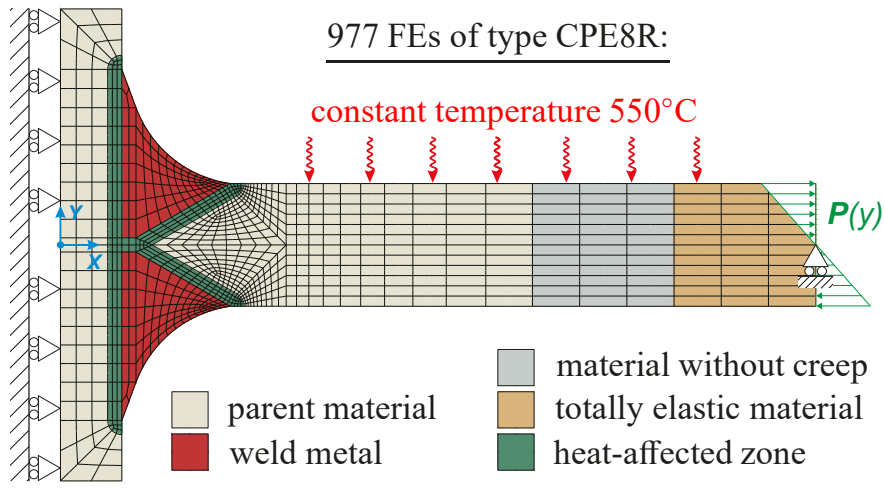

Figure 2: Parameters of the finite element mesh with designation of different materials, boundary conditions and mechanical loading

analysis technique using recent improvements of LMM [2]. So that a more accurate prediction of the experimental data $[3,4,5]$ with less conservatism can be made compared with previous analyses, particularly with [10].

\section{Structural model}

The geometry of the weldment specimen, shown schematically in Fig. 1, is reconstructed from [3] based on the given sketches of the cruciform weldment specimen and the Manual Metal Arc (MMA) welding procedure. A continuous plate of width $200 \mathrm{~mm}$ and length of $1.8 \mathrm{~m}$ is divided, at its centre, into two parts, each of which is welded to the surface of a third plate of length $100 \mathrm{~mm}$. Thus, a cruciform specimen consists of 4 identical welds transverse to the principal plate direction and symmetrically placed relative to the middle planes. The general approach to the description of a typical weld subdivides the material into three regions: the parent material, assumed to be uniform away from the weld; the weld metal, deposited material during multi-pass welding process; and the heat-affected zone (HAZ), a thin layer between the weld and parent material. It should be noticed that the thickness of HAZ of $3 \mathrm{~mm}$ is estimated based on available micrographs of similar cruciform weldments microstructure with indistinct boundaries between weld regions. The welding process used AISI $316 \mathrm{~N}(\mathrm{~L})$ as a filler material, and so the the joint is made from this material throughout. Despite this, these regions are expected to 

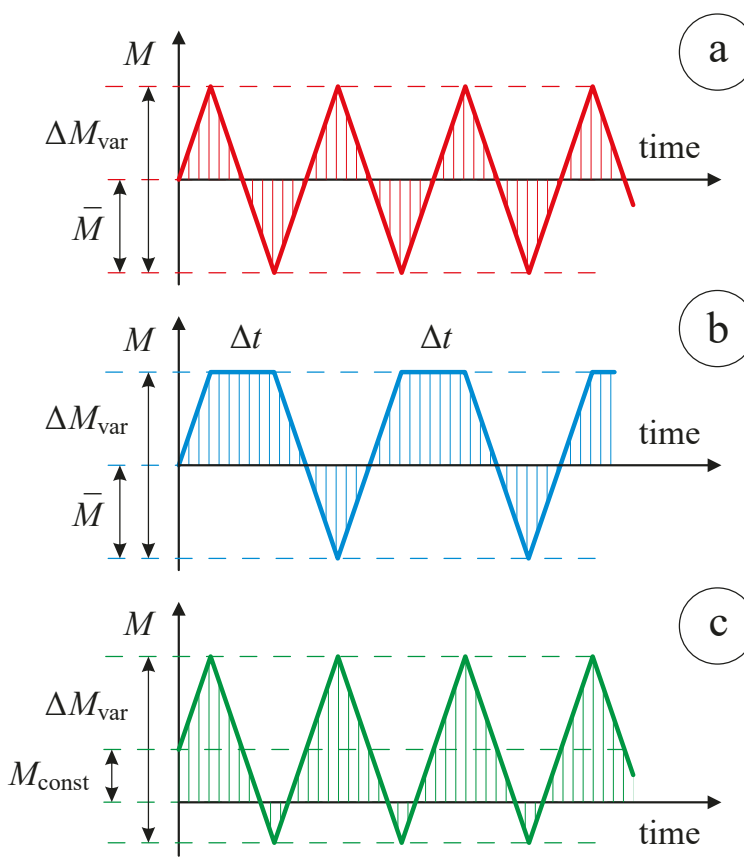

Figure 3: Assumed schematic loading history for the bending moment $M$ in: a) fully-reversed pure fatigue tests; b) fully-reversed creep-fatigue tests with dwells $\Lambda t$ in tension; c) non-symmetric pure fatigue tests

have different mechanical properties including elasticity, plasticity, fatigue and creep, caused by microstructural transformations during the multi-pass welding process. The experimental data corresponding to mechanical properties of different weld regions are described by the conventional models, and appropriate material constants at $550^{\circ} \mathrm{C}$ used for LMM are discussed in the next section.

The FE-mesh for a 2D symmetric model of the cruciform specimen is shown in Fig. 2 assuming a plane strain conditions since the specimen width $(200 \mathrm{~mm})$ is almost by an order of magnitude greater than the specimen thickness $(26 \mathrm{~mm})$ according to Fig. 1. The FE-mesh includes 5 separate areas with different material properties: 1) parent material, 2) HAZ, 3) weld metal, 4) material without creep, 5) totally elastic material. Introduction of 2 additional material types (material without creep and totally elastic material) representing reduced sets of parent material properties in the location of bending moment application avoids excessive stress concentrations in ratcheting and creep analysis. The FE-model consists of 977 finite elements of type CPE8R: 8-node biquadratic plane strain quadrilaterals with reduced integration.

Referring to the technical details $[3,4,5,6]$ the testing was performed at $550 \pm 3^{\circ} \mathrm{C}$ under fully-reversed 4-point bending with total strain ranges $\Delta \varepsilon_{\text {tot }}$ of $0.25,0.3,0.4,0.6$ or $1.0 \%$ and hold periods $\Delta t$ of 0,1 or 5 hours using a strain rate of $0.03 \% / \mathrm{s}$. Controlling of central specimen displacement was subsequently used to keep $\Delta \varepsilon_{\text {tot }}=$ const at maximum deflection during a period on the outer fiber of parent plate material remote from weld and HAZ regions. For the purpose of shakedown and creep analysis using LMM, the conversion from strain-controlled test conditions to force-controlled loading in simulations has been carried out. Although the gradual increase of applied loading during the initial cycles [4] demonstrate significant cyclic hardening effects of the specimen material behaviour, which is typical for the steel AISI type $316 \mathrm{~N}(\mathrm{~L})$, such a simplification is valid considering that saturated cyclic structural response is dominant during the whole duration of tests.

Therefore, in numerical simulations the arms of the specimen are subjected to 3 variants of bending moment history illustrated schematically in Fig. 3. Pure fatigue analysis assumes a rapid reversal of bending moment of magnitude $\Delta M_{\mathrm{var}}$ as shown in Fig. 3a. Creep-fatigue analysis assumes a rapid reversal of bending moment of magnitude $\Delta M_{\mathrm{var}}$ separated by dwell periods of duration $\Delta t$ when the moment is maintained constant at $\bar{M}=\Delta M_{\mathrm{var}} / 2$ as shown in Fig. $3 \mathrm{~b}$. Shakedown analysis assumes compound bending moment consisting of variable component of magnitude $\Delta M_{\mathrm{var}}$ and constant shift of value $M_{\text {const }}$, hereby forming a load space as shown in Fig. 3c.

Another effective analysis technique comprises application of bending moment through the linear distribution of normal pressure $P$ over the section of plate as shown in Fig. 2 with the area moment of inertia in regard to horizontal axis $X$ :

$$
I_{X}=a \cdot b^{3} / 12,
$$

where the width of plate $a=200 \mathrm{~mm}$ and the thickness of plate $b=26 \mathrm{~mm}$. Hereby, the normal pressure is expressed in terms of applied bending moment $M$ and vertical coordinate $y$ of plate section assuming the coordinate origin in the mid-surface:

$$
P(y)=M \cdot y / I_{X}
$$

\section{Material models and constants}

Mechanical properties of the materials composing cruciform weldment manufactured of the steel AISI type $316 \mathrm{~N}(\mathrm{~L})$ include the following material behaviour models and corresponding constants at $550^{\circ} \mathrm{C}$ :

- Elastic-perfectly-plastic (EPP) model for the design limits as result of shakedown analysis;

- Ramberg-Osgood (R-O) model for the plastic and total strains under saturated cyclic conditions;

- S-N diagrams for the number of cycles to failure caused by pure low-cycle fatigue (LCF);

- Power-law model in "time hardening" form for creep strains during primary creep stage;

- Reverse power-law relation for the time to creep rupture caused by creep relaxation during dwells;

- Non-linear diagrams for creep-fatigue damage interaction for the estimation of total damage. 
Table 1: Material parameters for the steel AISI type $316 \mathrm{~N}(\mathrm{~L})$ corresponding to elastic and saturated cyclic plasticity properties at $550^{\circ} \mathrm{C}$, after [3]

\begin{tabular}{l|llll}
\hline \hline Zone & $E(\mathrm{MPa})$ & $B(\mathrm{MPa})$ & $\beta$ & $\sigma_{\mathrm{y}}(\mathrm{MPa})$ \\
\hline Parent & 160000 & 1741.96 & 0.29960 & 270.662 \\
Weld & 122000 & 578.99 & 0.10162 & 307.894 \\
HAZ & 154000 & 1632.31 & 0.25304 & 338.731 \\
\hline \hline
\end{tabular}

\subsection{Cyclic plasticity}

The cyclic stress-strain properties of the steel AISI type $316 \mathrm{~N}(\mathrm{~L})$ parent material and associated weld and HAZ metals have been determined in a separate programme of uniaxial materials tests [3]. These data are presented in terms of the conventional Ramberg-Osgood equation to describe the nonlinear relationship between stress and strain in materials near their yield points. It is especially useful for metals that harden with plastic deformation, showing a smooth elastic-plastic transition, such as the steel AISI type $316 \mathrm{~N}(\mathrm{~L})$ at high temperatures. The equation for the cyclic stress-strain curve implemented in LMM code for the creep-fatigue analysis is following

$$
\frac{\Delta \varepsilon_{\text {tot }}}{2}=\frac{\Delta \sigma}{2 E}+\left(\frac{\Delta \sigma}{2 B}\right)^{1 / \beta},
$$

where $\Delta \varepsilon_{\text {tot }}$ is the total strain range; $\Delta \sigma$ is the total stress range in $\mathrm{MPa} ; B$ and $\beta$ are material constants; $\bar{E}$ is the effective elastic modulus in MPa defined as

$$
\bar{E}=\frac{3 E}{2(1+v)},
$$

where the Young's modulus $E$ in MPa and the Poisson's ratio $v$ are the elastic properties used in both R-O and EPP models.

The material constants for the parent, weld and HAZ materials at $550^{\circ} \mathrm{C}$ presented in [3] corresponding to the saturated cyclic behaviour are reported in Table 1. The Poisson's ratio at $550^{\circ} \mathrm{C}$ for all materials is assumed to be $v=0.3$. The yield stress $\sigma_{\mathrm{y}}$, taken as the stress corresponding to $0.2 \%$ of plastic strain defined by Eq. (3) for saturated cyclic stress-strain curve, is implemented in LMM code for the shakedown analysis.

\subsection{Low-cycle fatigue}

The dependence of total strain range $\Delta \varepsilon_{\text {tot }}$ in $\%$ on the number of cycles to LCF failure $N^{*}$ is usually defined by a quadratic polynomial function (e.g. see [9]) to remove the small amount of scatter in results on S-N diagram as follows

$$
\log \left(\Delta \varepsilon_{\text {tot }}\right)=m_{0}+m_{1} \log \left(N^{*}\right)+m_{2} \log \left(N^{*}\right)^{2},
$$

where $m_{0}, m_{1}$ and $m_{2}$ are the coefficients of polynomial (5) defined by fitting the experimental data. The reverse relation for Eq. (5) is more interesting for practical application and obtained as the root of square equation as follows [9]

$$
\log \left(N^{*}\right)=\frac{-m_{1}-\sqrt{m_{1}^{2}-4 m_{2}\left[m_{0}-\log \left(\Delta \varepsilon_{\text {tot }}\right)\right]}}{2 m_{2}} .
$$

Table 2: Polynomial coefficients of Eqs (5) and (7) for R66 endurance curves [9] of the steel AISI type $316 \mathrm{~N}(\mathrm{~L})$ corresponding to LCF properties at $550^{\circ} \mathrm{C}$

\begin{tabular}{l|ll|ll}
\hline \hline & \multicolumn{2}{|c|}{ Quadratic } & \multicolumn{2}{c}{ Cubic } \\
\cline { 2 - 5 } & Parent & Weld & Parent & Weld \\
\hline$m_{0}$ & 1.73339 & 1.85169 & 2.40906 & 1.93432 \\
$m_{1}$ & -0.72959 & -0.76094 & -1.25128 & -0.82500 \\
$m_{2}$ & 0.06170 & 0.05951 & 0.19399 & 0.07585 \\
$m_{3}$ & & & -0.01102 & -0.00137 \\
\hline \hline
\end{tabular}

More accurate representation of S-N diagram is provided by the cubic polynomial function in the following form

$$
\begin{aligned}
& \log \left(\Delta \varepsilon_{\text {tot }}\right)=m_{0}+m_{1} \log \left(N^{*}\right)+m_{2} \log \left(N^{*}\right)^{2}+ \\
& +m_{3} \log \left(N^{*}\right)^{3},
\end{aligned}
$$

where $m_{0}, m_{1}, m_{2}$ and $m_{3}$ are the coefficients of polynomial (7) defined by fitting the experimental data. Finding the root of the corresponding to Eq. (7) cubic equation to define $N^{*}$ is more complicated and achieved in several steps as follows

$$
\begin{aligned}
& \log \left(N^{*}\right)=C_{1}+C_{2}-\frac{m_{2}}{3 m_{3}}, \\
& C_{1}=\left(\sqrt{C_{3}}-\frac{C_{5}}{2}\right)^{1 / 3}, C_{2}=\left(-\sqrt{C_{3}}-\frac{C_{5}}{2}\right)^{1 / 3}, \\
& C_{3}=\left(\frac{C_{5}}{2}\right)^{2}+\left(\frac{C_{4}}{3}\right)^{3}, C_{4}=-\frac{1}{3}\left(\frac{m_{2}}{m_{3}}\right)^{2}+\frac{m_{1}}{m_{3}}, \\
& C_{5}=\frac{2}{27}\left(\frac{m_{2}}{m_{3}}\right)^{3}-\frac{m_{2} m_{1}}{3 m_{3}^{2}}+\frac{m_{0}-\log \left(\Delta \varepsilon_{\mathrm{tot}}\right)}{m_{3}} .
\end{aligned}
$$

R66 endurance curves for parent and weld material of the steel AISI type $316 \mathrm{~N}(\mathrm{~L})$ at $550^{\circ} \mathrm{C}$ reported in [9] are fitted by the both polynomial functions (5) and (7) in order to define the corresponding polynomial coefficients listed in Table 2 for employment in creep-fatigue analysis.

\subsection{Creep strain and rupture}

The most convenient and simple relation to describe primary creep strain among all the available creep models [21] is the conventional "time hardening" form of power-law model or the Norton-Bailey equation in uniaxial form:

$$
\dot{\varepsilon}^{\mathrm{cr}}=A \sigma^{n} t^{m} .
$$

Integrating Eq. (9) gives the relation for creep strain:

$$
\varepsilon^{\mathrm{cr}}=[A /(m+1)] \sigma^{n} t^{m+1},
$$

where $\varepsilon^{\mathrm{cr}}$ is the creep strain, $\sigma$ is the applied stress in MPa, $t$ is the time in hours, $A, n$ and $m$ are the creep material constants identified by fitting Eq. (10) to the primary stage of experimental creep curves. The available creep strain data for the steel AISI type $316 \mathrm{~N}(\mathrm{~L})$ at $550^{\circ} \mathrm{C}$ have been determined in a separate programme of uniaxial materials tests and reported in [3] in the form of creep curves at several stress levels:

- parent material at 390, 349, 310 and $285 \mathrm{MPa}$;

- associated MMA weld metal at 270,250 and $215 \mathrm{MPa}$. 
Table 3: Creep constants for the steel AISI type $316 \mathrm{~N}(\mathrm{~L})$ at $550^{\circ} \mathrm{C}$ identified using experimental data for creep strain rupture of weldments [3,22]

\begin{tabular}{l|lll|ll}
\hline \hline \multirow{2}{*}{ Zone } & \multicolumn{3}{|c|}{ Primary creep strain } & \multicolumn{2}{c}{ Creep rupture } \\
\cline { 2 - 6 } & $A\left(\frac{\mathrm{MPa}^{-n}}{\mathrm{~h}^{m+1}}\right)$ & $n$ & $m$ & $B\left(\mathrm{MPa}^{k} \mathrm{~h}\right)$ & $k$ \\
\hline Parent & $6.604 \mathrm{E}-19$ & 5.769 & -0.55 & $2.172 \mathrm{E}+26$ & 8.927 \\
Weld & $6.597 \mathrm{E}-23$ & 7.596 & -0.5 & $5.993 \mathrm{E}+29$ & 10.61 \\
HAZ & $6.600 \mathrm{E}-21$ & 6.683 & -0.525 & $1.291 \mathrm{E}+28$ & 9.768 \\
\hline \hline
\end{tabular}

It should be noted that experimental creep strains accumulated during primary stage corresponding to different stress levels are fitted by employing the least squares method to define constants $A$ and $n$ and by estimation of average value of constant $m$. No creep curves are available for the HAZ, therefore the required creep constants are identified either by simple averaging of constants $(n, m)$ for parent material and MMA weld metal or by logarithmic averaging, where there are orders of magnitude separating the values of constants $(A)$. Values of constants used with LMM are listed in Table 3.

The next critical parameter after accumulated creep strain $\varepsilon^{\text {cr }}$ is time to creep rupture $t^{*}$, which is also dependent on stress $\sigma$ and conventionally described by the reverse power-law:

$$
t^{*}=B \sigma^{-k},
$$

where $B$ and $k$ are the creep material constants identified by fitting Eq. (11) to the experimental creep rupture data using the least squares method. Constants for the parent material are identified using 4 experimental values from [3]. Since the 3 experimental values for the MMA weld metal given in [3] may not be sufficient for accurate determination of the constants, the experimental data in [22] are employed for weld metal constants. Constants for the HAZ are identified by averaging parent and weld properties in the same way as for the creep constants. Values of constants used in creep-damage assessment are listed in Table 3.

\section{Structural integrity assessments}

\subsection{Design limits analysis}

The limit load, shakedown limit and ratchet limit were evaluated with an elastic-perfectly-plastic (EPP) model and a von Mises yield condition using material properties corresponding to saturated cyclic plasticity response $\left(E, \sigma_{\mathrm{y}}\right.$ and $\left.v\right)$ reported in Table 1. Referring to Sect. 2 the history of bending moment for shakedown analysis is assumed as $M=M_{\text {const }} \pm \bar{M}$ where $\bar{M}=\Delta M_{\mathrm{var}} / 2$ as shown in Fig. 3c. The sequence of shakedown FE-analyses was carried out using the variant of LMM $[16,17]$ capable of upper and lower ratchet limit identification. The resultant boundaries are shown in the Bree interaction diagram in Fig. 4 , in coordinate space of $\left[M_{\text {const }} / M_{\text {lim }}\right]$ and $\left[\Delta M_{\mathrm{var}} / \Delta M_{\mathrm{sh}}\right.$, where $M_{\mathrm{lim}}$ and $\Delta M_{\mathrm{sh}}$ denote the limit moment and shakedown limit respectively. The values of $M_{\text {lim }}$ and $\Delta M_{\mathrm{sh}}$ are identified using standard inelastic FE-analysis with EPP material model for the conditions of structural collapse and yield initiation respectively: $M_{\lim }=10559430(\mathrm{~N} \mathrm{~mm})$

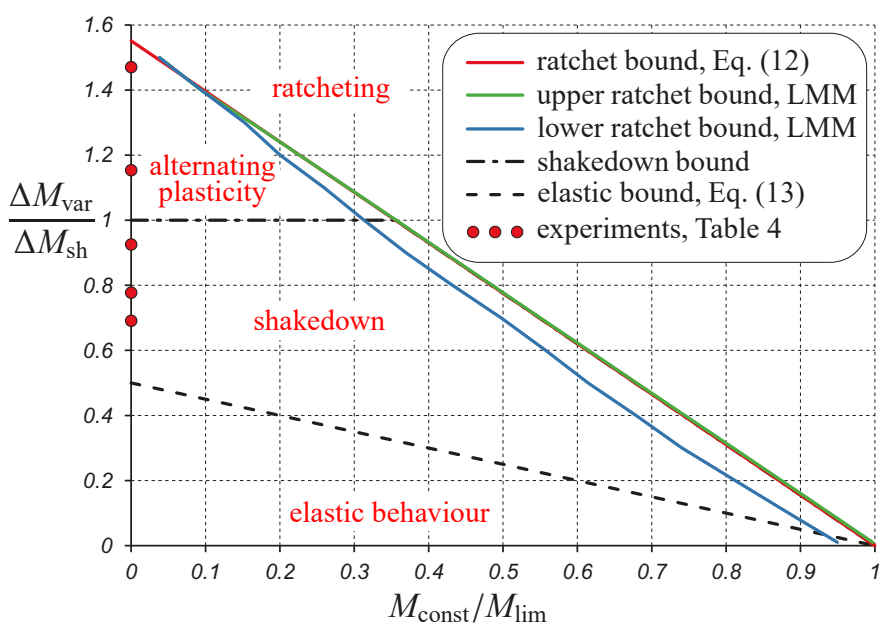

Figure 4: The Bree interaction diagram for cruciform weldment subjected to cyclic reverse bending moment $\Delta M_{\mathrm{var}}$ and constant bending moment $M_{\text {const }}$

and $\Delta M_{\mathrm{sh}}=13614160(\mathrm{Nmm})$. The normalised moment is defined as the relation of variable moment range to shakedown limit: $\tilde{M}=\Delta M_{\mathrm{var}} / \Delta M_{\mathrm{sh}}$. Therefore, the maximum normalised moment defined as the relation of limit moment range $\Delta M_{\text {lim }}$ to $\Delta M_{\mathrm{sh}}$ has the following value: $\tilde{M}_{\max }=\Delta M_{\mathrm{lim}} / \Delta M_{\mathrm{sh}}=$ 1.55124. The Bree diagram in Fig. 4 is divided into four regions: elastic behaviour, shakedown, alternating plasticity, and ratcheting.

In the specific case of a cruciform weldment specimen under pure bending moment and constant temperature the analytical ratchet bound is described by the straight-line equation:

$$
\left[\Delta M_{\mathrm{var}} / \Delta M_{\mathrm{sh}}\right]=-\tilde{M}_{\max }\left[M_{\mathrm{const}} / M_{\mathrm{lim}}\right]+\tilde{M}_{\max },
$$

which is confirmed by the numerical upper and lower ratchet bounds identified by LMM as observed in Fig. 4.

Thus, the analytical elastic bound has the similar form:

$$
\left[\Delta M_{\mathrm{var}} / \Delta M_{\mathrm{sh}}\right]=-0.5\left[M_{\text {const }} / M_{\text {lim }}\right]+0.5 \text {. }
$$

Hereby, for the specific case of cruciform weldment specimen under fully-reversed bending moment the estimated design limits for allowable loading $\Delta M_{\mathrm{var}}$ are from $\Delta M_{\min }=0.5 \Delta M_{\mathrm{sh}}$ to $\Delta M_{\max }=1.55124 \Delta M_{\mathrm{sh}}$.

\subsection{Creep-fatigue evaluation procedure}

The basic routine of the proposed evaluation procedure for creep-fatigue damage assessment of cruciform weldments is the same as of the PNC time fraction procedure developed by the Power Reactor and Nuclear Fuel Development Corporation (Ibaraki, Japan). The PNC procedure using the time fraction rule to evaluate creep damage was initially developed for austenitic stainless steels (type 304 and 316FR) giving good creep-fatigue life estimation [23]. This method has also been shown to be applicable to other temperature-resistant steels to describe various material behaviour effects. In addition to cyclic strain hardening [23] in austenitic steels, they also include cyclic strain softening [24] in martensitic steels such as modified 9Cr-1Mo steel, both hardening and softening in different weldment zones [25] in type 304 SS butt welded joints, 
environmental effects such as oxidation, elastic follow-up, etc. Therefore, the PNC procedure has been accepted for design applications, e.g. LMFBR structural components, and became a basis for Monju Structural Design Guide.

There are two key differences between the PNC procedure and the proposed procedure - the former one is based on elastic analysis and operates with the secondary creep model while the latter one is based on inelastic analysis using LMM and operates with the primary creep model. An inelastic analysis using LMM and considering both cyclic plasticity (3) and transient creep effects enables automatic estimation of the elastic follow-up factor in critical locations. Employment of primary creep model in "time-hardening" form (9) instead of secondary creep model is motivated by significant hardening effects in all weldment materials of the steel AISI type $316 \mathrm{~N}(\mathrm{~L})$. Moreover, Eq. (9) provides slightly conservative solution of the creep-relaxation problem in terms of estimated creep strain and stress reduction compared to primary "strain-hardening" and secondary power-law models. Therefore, the benefit of the proposed evaluation procedure compared to the PNC procedure is that it is expected to provide more accurate saturated cyclic response of the structure under creep-fatigue conditions.

The general concept of the proposed creep-fatigue evaluation procedure considering time fraction rule for creep-damage assessment is illustrated on Fig. 5 and consists of 5 steps:

1. Estimation of saturated hysteresis loop using LMM;

2. Estimation of fatigue damage using S-N diagram;

3. Assessment of stress relaxation with elastic follow-up;

4. Estimation of creep damage using creep rupture curve;

5. Estimation of total damage using interaction diagram.

Step 1: Saturated hysteresis loop. This step involves inelastic FEA using LMM in CAE-system ABAQUS incorporating FORTRAN user material subroutine UMAT. This subroutine includes implementation of Ramberg-Osgood cyclic plasticity model (3) and primary creep model in "time-hardening" form (9) with material constants from Tables 1 and 3 respectively. For detailed description of numerical procedure for the creep strain and flow stress estimation in the LMM code refer to [2], for a general guide to the LMM implementation using the ABAQUS user subroutines refer to [19]. The modification of the original LMM code [2] implemented in the given research comprises the conversion from EPP model to R-O model, which provides more reasonable stress response for the total strain ranges $\Delta \varepsilon_{\text {tot }}$ in cruciform weldment testing [3, 4,5]. For this specific case, the schematic creep-fatigue hysteresis loop with dwell at tensile cycle peak is shown in Fig. 5. The FEA outputs the results of saturated cyclic structural response in terms of effective strains and effective von Mises stresses for 3 load instances: 1) end of direct loading, 2) end of dwell period, 3) end of reverse loading. For example, the following parameters of the saturated hysteresis loop are defined: plastic and elastic strains at direct and reverse loading $\left(\varepsilon_{1}^{\mathrm{el}}, \varepsilon_{1}^{\mathrm{pl}}, \varepsilon_{3}^{\mathrm{el}}, \varepsilon_{3}^{\mathrm{pl}}\right)$; creep strain $\varepsilon^{\mathrm{cr}}$ accumulated during dwell $\Delta t$; ratchet strain accumulated over cycle $\varepsilon_{\text {rat }}$; total strain range over cycle $\Delta \varepsilon_{\text {tot }}$; cyclic stresses (comprising elastic, constant and varying resid-
Table 4: The values of normalised moment $\tilde{M}$ corresponding to the values of total strain range $\Delta \varepsilon_{\text {tot }}$ from experiments $[3,4,5]$ defined by LMM

\begin{tabular}{c|ccccc}
\hline \hline$\Delta \varepsilon_{\text {tot }}, \%$ & 1.0 & 0.6 & 0.4 & 0.3 & 0.25 \\
\hline$\dot{M}$ & 1.4705 & 1.1538 & 0.9255 & 0.7774 & 0.691 \\
\hline \hline
\end{tabular}

ual stresses) at each load instance $\left(\sigma_{1}, \sigma_{2}, \sigma_{3}\right)$; drop of stress $\Delta \sigma_{\text {cr }}$ during dwell $\Delta t$; and elastic follow-up factor $Z$ :

$$
Z=\bar{E} \varepsilon^{\mathrm{cr}} / \Delta \sigma_{\mathrm{cr}},
$$

where the effective elastic modulus $\bar{E}$ is defined by Eq. (4).

Among all these output parameters the most important for further creep-fatigue evaluation are total strain range $\Delta \varepsilon_{\text {tot }}$, stress $\sigma_{1}$ in the beginning of dwell period and elastic follow-up factor $Z$. It should be noted that the LMM could be also applied to complex loading histories exceeding more then 3 load instances, refer to e.g. [16].

The values of normalised moment $\tilde{M}$ corresponding to the values of total strain range $\Delta \varepsilon_{\text {tot }}$ from experiments $[3,4,5]$ defined by LMM are reported in Table 4 and shown as circles in Fig. 4 and lie within both the alternating plasticity and shakedown regions. This fact shows that the experiments capture comprehensively the critical area of cyclic structural response relevant to engineering analysis of structural integrity.

Step 2: Fatigue damage. This step is based upon the total strain range $\left(\Delta \varepsilon_{\text {tot }}\right)$ values identified in Step 1 and square (5) or cubic (7) polynomial functions for $\mathrm{S}-\mathrm{N}$ diagrams characterising LCF properties in Sect. 3.2. Thus, the number of cycles to pure fatigue failure $N^{*}$ corresponding to particular value of $\Delta \varepsilon_{\text {tot }}$ in critical location is defined either by Eq. (6) or by Eq. (8) with polynomial coefficients in Table 2 for R66 fatigue endurance curves [9] of the steel AISI type $316 \mathrm{~N}(\mathrm{~L})$. Therefore, the fatigue damage accumulated per 1 cycle is

$$
\omega_{1 \mathrm{c}}^{\mathrm{f}}=1 / N^{*}\left(\Delta \varepsilon_{\text {tot }}\right) .
$$

Step 3: Stress relaxation. This step is based upon the relaxation problem with elastic follow-up generally formulated as

$$
\frac{d \varepsilon^{\mathrm{cr}}}{d t}+\frac{Z}{E} \frac{d \sigma}{d t}=0
$$

which has the following analytical solution for stress function in case of "time-hardening" form (9) of the creep model $\dot{\varepsilon}^{\text {cr. }}$ :

$$
\sigma\left(t, Z, \sigma_{1}\right)=\left[\sigma_{1}{ }^{1-n}-\frac{t^{m+1} \bar{E} A(1-n)}{Z(m+1)}\right]^{1 /(1-n)},
$$

and creep strain accumulated during relaxation is

$$
\varepsilon^{\mathrm{cr}}=\left[\sigma_{1}-\sigma\left(t, Z, \sigma_{1}\right)\right] Z / \bar{E},
$$

where the values of elastic follow-up factor $Z$ and stress $\sigma_{1}$ in the beginning of dwell period $\Delta t$ are taken from Step 1; and $A$, $n$ and $m$ are creep material constants for Eq. (9) from Table 3.

The main purpose of such reconstruction of stress relaxation behaviour is the estimation of the average stress $\bar{\sigma}$ over the dwell period $\Delta t$. It would not be correct to define $\bar{\sigma}$ by simple averaging of $\sigma_{1}$ and $\sigma_{2}$, because the function (17) is highly 


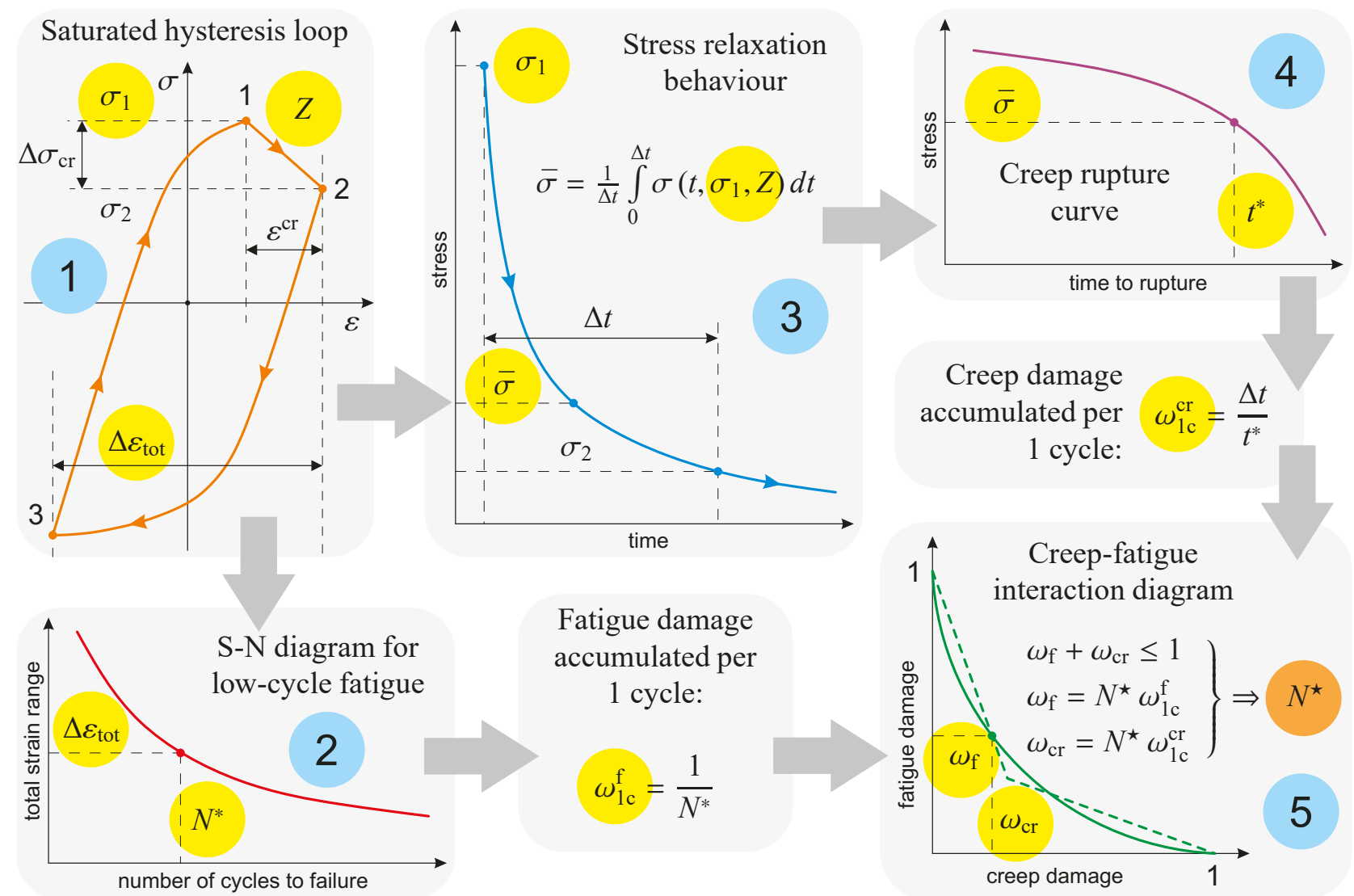

Figure 5: The general concept of creep-fatigue evaluation procedure considering time fraction rule for creep-damage assessment

non-linear for long-term dwells $\Delta t$. Therefore, $\bar{\sigma}$ is defined as a mean value of the integrable function $\sigma\left(t, Z, \sigma_{1}\right)$ on some closed interval $t \in[0 \ldots \Delta t]$. Since, the function (17) is not integrable analytically, this integral is estimated numerically:

$$
\bar{\sigma}\left(\Delta t, \sigma_{1}, Z\right)=\frac{1}{\Delta t} \int_{0}^{\Delta t} \sigma\left(t, \sigma_{1}, Z\right) d t
$$

Step 4: Creep damage. This step is based upon the average stress $\bar{\sigma}$ values identified in Step 3 and creep rupture curves described by the reverse power-law (11) characterising creep properties in Sect. 3.3. Thus, the time to pure creep rupture $t^{*}$ corresponding to a particular value of $\bar{\sigma}$ in critical locations is defined by Eq. (11) with creep constants $B$ and $k$ from Table 3 based on experimental data [3,22] for the steel AISI type $316 \mathrm{~N}(\mathrm{~L})$. Therefore, the creep damage accumulated per 1 cycle considering time fraction rule is

$$
\omega_{1 \mathrm{c}}^{\mathrm{cr}}=\Delta t / t^{*}(\bar{\sigma})
$$

It should be noted that the proposed procedure as well as the PNC procedure $[23,24,25]$ implements linear damage summation and time fraction rules for the creep damage assessment in contrast to the R5 Procedure [11], which is based on creep ductility exhaustion rule:

$$
\omega_{1 \mathrm{c}}^{\mathrm{cr}}=\varepsilon^{\mathrm{cr}} / \varepsilon^{*},
$$

where $\varepsilon^{\mathrm{cr}}$ is creep strain accumulated during dwell period $\Delta t$, and $\varepsilon^{*}$ is creep strain at rupture or creep ductility, which can be considered as stress-dependent.
Referring to [26] an employment of ductility exhaustion rule (21) without excessive conservatism in the predictions requires non-linear damage summation assuming variation of damage with cycles. Such an approach is not implementable in the LMM which, as any direct analysis method, is able to output only parameters of the saturated cyclic structural response. Thus, the time fraction rule is employed in the proposed procedure, because it is less sensitive to the simplification of the nature of non-linear damage summation to linear.

Step 5: Creep-fatigue interaction. This step is based upon the values of fatigue damage $\omega_{\mathrm{f}}=N^{\star} \omega_{1 \mathrm{c}}^{\mathrm{f}}$ and creep damage $\omega_{\text {cr }}=N^{\star} \omega_{1 \mathrm{c}}^{\mathrm{cr}}$ accumulated during the whole service period of the structure until crack initiation, which is characterised by the total number of cycles $N^{\star}$ under creep-fatigue interaction conditions. The components of damage per cycle $\left(\omega_{1 \mathrm{c}}^{\mathrm{f}}\right.$ and $\left.\omega_{1 \mathrm{c}}^{\mathrm{cr}}\right)$ are taken from Step 2 and Step 4 respectively. The key output of evaluation procedure $N^{\star}$ is usually defined assuming a key idea of CDM that the sum of the damage parameters can't exceed 1:

$$
\omega_{\mathrm{f}}+\omega_{\mathrm{cr}} \leq 1,
$$

employing the damage interaction diagrams [27], where fatigue and creep components of damage are plotted on separate axes.

The most commonly used damage interaction diagrams (such as those in ASME N47 and RCC-MR procedures) have a bilinear damage locus, where $\omega_{\mathrm{cr}}=0 \rightarrow \omega_{\mathrm{f}}=1, \omega_{\mathrm{cr}}=1 \rightarrow \omega_{\mathrm{f}}=$ 0 and $\omega_{\mathrm{f}}+\omega_{\mathrm{cr}}<1$ for the rest of locations. The coordinates of 


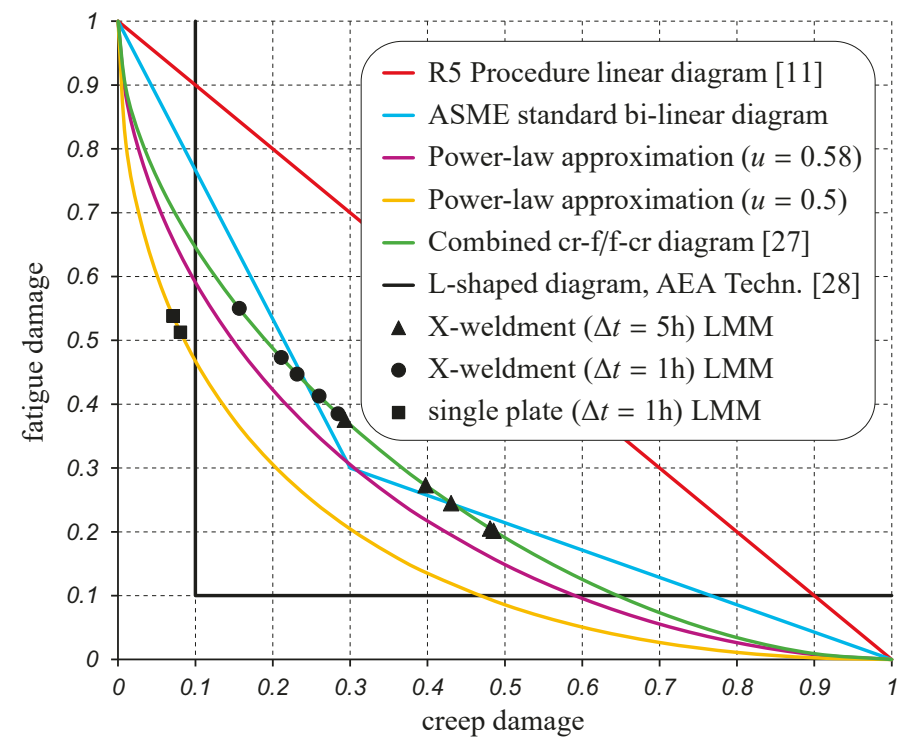

Figure 6: Creep-fatigue damage interaction diagrams and results of LMM

intersection $(c, f)$ of the two lines is given by [27]:

$$
\begin{array}{ll}
\omega_{\mathrm{f}}=1-\left[\omega_{\mathrm{cr}}(1-f) / c\right] & \text { for } \omega_{\mathrm{cr}}<c, \\
\omega_{\mathrm{f}}=f\left(1-\omega_{\mathrm{cr}}\right) /(1-c) & \text { otherwise, }
\end{array}
$$

where the coordinates $(c, f)$ have unique values for different types of steels [27], e.g. $(0.02,0.1)$ for Mod. $9 \mathrm{Cr}-1 \mathrm{Mo}$, $(0.14,0.12)$ for $2.25 \mathrm{Cr} 1 \mathrm{Mo}$ and Alloy $800 \mathrm{H}$, and $(0.3,0.3)$ for type $316 \mathrm{~N}(\mathrm{~L})$ as shown in Fig. 6 . Therefore, $N^{\star}$ is evaluated as

$$
\begin{array}{ll}
N^{\star}=\left(\omega_{1 \mathrm{c}}^{\mathrm{f}}+\left[\omega_{1 \mathrm{c}}^{\mathrm{cr}}(1-f) / c\right]\right)^{-1} & \text { for } \omega_{1 \mathrm{c}}^{\mathrm{cr}}>\omega_{1 \mathrm{c}}^{\mathrm{f}}, \\
N^{\star}=\left(\left[\omega_{1 \mathrm{c}}^{\mathrm{f}}(1-c)+\omega_{1 \mathrm{c}}^{\mathrm{cr}}\right] / f\right)^{-1} & \text { otherwise. }
\end{array}
$$

For ease in calculation in [27], the discontinuous function (23) is replaced with the following power-law approximation:

$$
\omega_{\mathrm{cr}}^{u}+\omega_{\mathrm{f}}^{u}=1
$$

where the exponent $u$ can also have different values. If $u=1$ then the linear diagram is obtained, which is employed in the R5 Procedure [11] and most suitable for damage assessment with the ductility exhaustion rule (21). If $u=0.58$ then the damage locus crosses the point $(0.3,0.3)$, what corresponds to the fitting of ASME and RCC-MR bi-linear diagram as shown in Fig. 6. If $u=0.5$ then referring to [29], a conservative damage locus is obtained, which agrees better with experimental data for the steel type $316 \mathrm{~N}(\mathrm{~L})$ and recommended for practical applications.

The solution for the power-law approximation (25) is

$$
N^{\star}=\left(\left[\omega_{1 \mathrm{c}}^{\mathrm{cr}}\right]^{u}+\left[\omega_{1 \mathrm{c}}^{\mathrm{f}}\right]^{u}\right)^{-1 / u} .
$$

If both "creep-fatigue" and "fatigue-creep" damage interactions are assumed to occur, a novel approach to construct the damage diagram was proposed in [27] based on "geometrical arguments" with the following equation:

$$
\frac{\omega_{\mathrm{f}}}{1-\omega_{\mathrm{cr}}}+\frac{\omega_{\mathrm{cr}}}{1-\omega_{\mathrm{f}}}=1
$$

which provides a very reasonable approximation to the ASME bi-linear diagram with intersection of $(0.3,0.3)$ as shown in
Fig. 6. However for the case of $\omega_{\mathrm{cr}}=\omega_{\mathrm{f}}$ it gives $(0.33,0.33)$. The parameter $N^{\star}$ is found by solving the quadratic equation:

$$
a N^{\star 2}-b N^{\star}+1=0
$$

where the root is

$$
\begin{aligned}
& N^{\star}=\left(-b-\sqrt{b^{2}-4 a c}\right) / 2 a \quad \text { with } \\
& a=\left[\omega_{1 \mathrm{c}}^{\mathrm{cr}}\right]^{2}+\left[\omega_{1 \mathrm{c}}^{\mathrm{f}}\right]^{2}+\omega_{1 \mathrm{c}}^{\mathrm{cr}} \omega_{1 \mathrm{c}}^{\mathrm{f}}, \quad b=2 \omega_{1 \mathrm{c}}^{\mathrm{cr}}+2 \omega_{1 \mathrm{c}}^{\mathrm{f}} .
\end{aligned}
$$

A relatively conservative approach for analysis of damage interaction was proposed by AEA Technology (now, Serco Assurance) in the form of L-shaped diagram [28] consisting of 2 orthogonal lines with intersection of $(0.1,0.1)$ as shown in Fig. 6. It is based on the results of creep-fatigue endurance tests covering a range of conditions and assumes

$$
\text { if } \omega_{\mathrm{cr}} \leq 0.1 \text {, then } \omega_{\mathrm{f}} \in[0 \ldots 1] \text {, else } \omega_{\mathrm{f}} \leq 0.1 \text {, }
$$

where the solution can be obtained in following form

$$
\begin{array}{ll}
N^{\star}=\min \left(0.1 / \omega_{1 \mathrm{c}}^{\mathrm{cr}} ; 1 / \omega_{1 \mathrm{c}}^{\mathrm{f}}\right) & \text { for } \omega_{1 \mathrm{c}}^{\mathrm{cr}}<\omega_{1 \mathrm{c}}^{\mathrm{f}}, \\
N^{\star}=\min \left(1 / \omega_{1 \mathrm{c}}^{\mathrm{cr}} ; 0.1 / \omega_{1 \mathrm{c}}^{\mathrm{f}}\right) & \text { otherwise. }
\end{array}
$$

The particular choice of the damage diagram for the practical application in the proposed procedure is achieved by the comparison of $N^{\star}$ produced by each of the available loci presented by Eqs $(23,25,27)$ and $(30)$ with experimental data $[3,4,5]$.

\section{Validation and handling of results}

\subsection{Validation against experiments}

The experimental studies of cruciform weldment $[3,4,5]$ have been simulated employing the FEA with the LMM based upon FE-model and loading conditions described in Sect. 2 and the material models described in Sect. 3. The outputs of the LMM have been processed by the proposed creep-fatigue evaluation procedure described in Sect. 4.2.

The initial validation of the proposed approach has been implemented for the parent material behaviour owing to the availability of experimental data [3] for fully-reversed bending of a single plate with total strain ranges $\Delta \varepsilon_{\text {tot }}$ of $0.55,0.7$, and $1.0 \%$ and hold period $\Delta t$ of 1 hour at $550^{\circ} \mathrm{C}$. The FEA has been performed for the 3 variants of normalised moment $\tilde{M}$ of $1.1024,1.2463$ and 1.4705 respectively and the same FE-model of cruciform weldment (Sect. 2) considering the measurement of LMM output results on the outer fiber of parent plate material remote from weld and HAZ regions. The creep-fatigue evaluation has been implemented operating with material properties for parent material only including R66 parent LCF endurance curve [9], creep rupture curve [3] and Eq. (25) for damage interaction with exponent $u=0.5$. Although this damage diagram (25) describes the most conservative locus compared to other concepts $(23,27,30)$ as shown in Fig. 6, it was found the most suitable among others since the number of cycles to failure $N^{\star}$ provided by its solution (26) shows good agreement with the experimental values as shown in Fig. 7. The location of resultant damage values in Fig. 6 for the single plate indicates that 


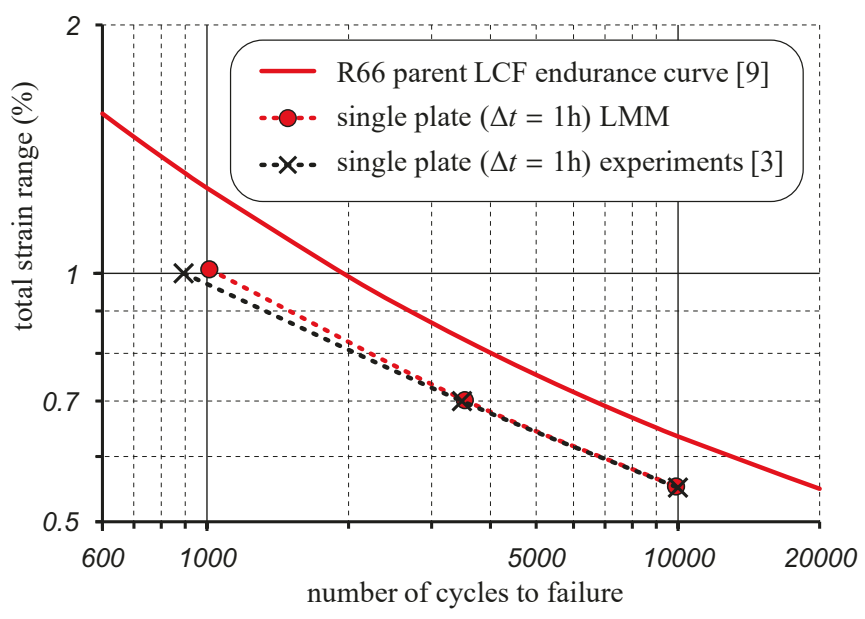

Figure 7: Results of creep-fatigue evaluation procedure in application to single plate and comparison with experimental data [3]

service conditions with $\Delta t=1$ hour shows that fatigue damage is dominant.

Since the proposed approach has proved its applicability in case of a single plate made of parent material, it has been applied to the assessment of a cruciform weldment considering different properties for the parent material, weld metal and HAZ. The 5 variants of normalised moment $\tilde{M}$ used in the FEA and their correspondence to $\Delta \varepsilon_{\text {tot }}$ in tests are listed in Table 4 . The complete summary of experimental and corresponding simulation conditions as well as outputs in the form of number of cycles to failure $N^{\star}$ and location of failure is reported in Table 5. It should be noted that in contrast to the case of the single plate, Eq. (27) considering both "creep-fatigue" and "fatigue-creep" damage interactions proposed in [27] has been applied in the evaluation procedure. This damage diagram (25) describes the moderate locus providing a reasonable approximation to the ASME N47 and RCC-MR bi-linear diagram as shown in Fig. 6. It was found the most suitable compared to other concepts $(23,27,30)$ since the number of cycles to failure $N^{\star}$ provided by corresponding solution (29) almost perfectly matches the experimental values as illustrated in Fig. 8. The location of resultant damage values in Fig. 6 for cruciform weldment indicates that service conditions with $\Delta t=1$ hour show that fatigue damage is dominant, whereas when $\Delta t$ is increased to 5 hours creep damage becomes dominant.

Visual comparison of the observed and predicted $N^{\star}$ in Fig. 8 for 3 variants of $\Delta t$ shows that 9 of the 11 simulations accurately predict the experimental results. From Table 5, however, it can be seen that the FEA simulations could not consistently predict the failure location. The LMM-based approach predicts failure in the weld toe for all experimental cases, whereas the experiments [5] observed crack initiation in 4 different locations: $(\mathrm{U})$ - specimen failed at the undercut close to the weld toe in the parent plate; $(\mathrm{T})$ - specimen failed at the weld toe with crack propagating through the HAZ; $(\mathrm{P})$ - specimen failed in parent plate remote from weld; $(\mathrm{W})$ - specimen failed in weld metal. Nevertheless, referring to [30] the creep-fatigue cracking in welded components of British Energy's Advanced
Gas Cooled Reactors made of the steel AISI type $316 \mathrm{~N}(\mathrm{~L})$ is generally observed at the weld toe with the crack propagating through the HAZ, which agrees with the predictions obtained by the proposed approach, see Table 5 .

A typical example of the location of critical damage accumulation corresponding to $\Delta \varepsilon_{\text {tot }}=1 \%$ on the outer fiber of the plate and $\Delta t=5$ hours of dwell period is illustrated in Fig. 9. It shows the outputs of the Step 1 of the proposed creepfatigue evaluation procedure described in Sect. 4.2 assuming estimation of the saturated hysteresis loop in a 3 load instance cycle using LMM. The distribution of total strain range $\Delta \varepsilon_{\text {tot }}$ with maximum value $\Delta \varepsilon_{\text {tot }}^{\max }=1.44 \%$ at the critical location is shown in Fig. 9a. The distribution of equivalent creep strain $\varepsilon^{\mathrm{cr}}$ at load instance 2 with maximum value $\varepsilon_{\max }^{\mathrm{cr}}=1.92156 \mathrm{E}-$ 3 at the critical location is shown in Fig. 9b. The distribution of equivalent von Mises stress $\sigma_{\mathrm{vM}}^{\mathrm{eq}}$ at the beginning of dwell at load instance 1 with maximum value $\sigma_{1}^{\mathrm{eq}}=330.88 \mathrm{MPa}$ at the critical location is shown in Fig. 9c. The distribution of equivalent von Mises stress $\sigma_{\mathrm{vM}}^{\mathrm{eq}}$ at the end of dwell at load instance 2 with maximum value $\sigma_{2}^{\text {eq }}=275.786 \mathrm{MPa}$ at the critical location is shown in Fig. 9d. Finally, the measured value of elastic follow up factor, $Z=4.9$, at the critical location agrees exactly with the analytical solution (17) for the stress $\sigma_{2}^{\text {eq }}=275.786 \mathrm{MPa}$ at the end of dwell period $\Delta t=5$ hours. It should be noted that all the above mentioned LMM results in the critical location have been measured at the same finite element and integration point using ABAQUS probe tool. Therefore, the maximum values measured at the integration point are slightly different from the maximum values on contour plot legends in Fig. 9 obtained by averaging of node results.

\subsection{Analytic assessment model}

Since the proposed approach has been successfully validated against experimental data (see Fig. 8) in Sect. 5.1, it can used for the formulation of an analytic assessment model suitable for the fast estimation of $N^{\star}$ for a variety of loading conditions. The low computational effort required by the LMM compared to other computational approaches makes it possible and relatively easy to extrapolate numerical predictions for loading conditions not captured by the available experimental studies $[3,4,5]$. This extrapolation comprises the extension of the dwell period $\Delta t$ duration up to 10000 hours, which is relevant to examples of practical industrial application of welded structures reported in [30]. A number of additional FE-simulations with LMM and sequent $N^{\star}$ estimations beyond the experimental loading conditions has been carried out, and their results are reported in Table 6 . The set of normalised moment values has been taken the same as in the experimental studies $[3,4,5]$, because it captures a large enough range of design limits $\tilde{M} \in[0.5 \ldots 1.5512]$, refer to Sect. 4.1.

The array of assessment results reported in Table 6 has been fitted using using the least squares method by the following function for the number of cycles to failure $N^{\star}$ dependent on arguments $\tilde{M}$ and $\Delta t$ and formulated in the form of power-law:

$$
\log \left(N^{\star}\right)=a(\Delta t) \tilde{M}^{-b(\Delta t)},
$$


Table 5: Comparison of LMM results for cruciform weldment with experimental data for pure fatigue and creep-fatigue tests [3, 4, 5]

\begin{tabular}{|c|c|c|c|c|c|c|c|c|c|c|c|c|}
\hline \multirow{3}{*}{$\begin{array}{c}\Delta \varepsilon_{\text {tot }} \\
\%\end{array}$} & \multicolumn{4}{|c|}{$\Delta t=0$ hours } & \multicolumn{4}{|c|}{$\overline{\Delta \Delta t=1 \text { hour }}$} & \multicolumn{4}{|c|}{$\overline{\Delta \Delta t=5 \text { hours }}$} \\
\hline & \multicolumn{2}{|c|}{ LMM } & \multicolumn{2}{|c|}{ experiments } & \multicolumn{2}{|c|}{ LMM } & \multicolumn{2}{|c|}{ experiments } & \multicolumn{2}{|c|}{ LMM } & \multicolumn{2}{|c|}{ experiments } \\
\hline & $N^{\star}$ & failure & $N^{\star}$ & failure & $N^{\star}$ & failure & $N^{\star}$ & failure & $N^{\star}$ & failure & $N^{\star}$ & failure \\
\hline 1 & 857 & $\mathrm{~T}$ & 918 & $\mathrm{~T}$ & 430 & $\mathrm{~T}$ & 562 & $\mathrm{U}$ & 278 & $\mathrm{~T}$ & 275 & $\mathrm{P}$ \\
\hline 0.6 & 4062 & $\mathrm{~T}$ & 2499 & $\mathrm{U}$ & 1673 & $\mathrm{~T}$ & 1048 & $\mathrm{U}$ & 967 & $\mathrm{~T}$ & 943 & W \\
\hline 0.4 & 17025 & $\mathrm{~T}$ & 15747 & $\mathrm{P}$ & 6270 & $\mathrm{~T}$ & 6512 & $\mathrm{U}$ & 3168 & $\mathrm{~T}$ & - & - \\
\hline 0.3 & 45374 & W & 38127 & $\mathrm{P}$ & 19776 & $\mathrm{~T}$ & 21488 & W & 9679 & $\mathrm{~T}$ & - & - \\
\hline 0.25 & 90056 & W & 66847 & $\mathrm{P}$ & 52221 & $\mathrm{~T}$ & - & - & 26901 & $\mathrm{~T}$ & - & - \\
\hline
\end{tabular}

(U) - specimen failed at the undercut close to the weld toe in the parent plate

(T) - specimen failed at the weld toe with crack propagating through the HAZ

(P) - specimen failed in parent plate remote from weld

(W) - specimen failed in weld metal

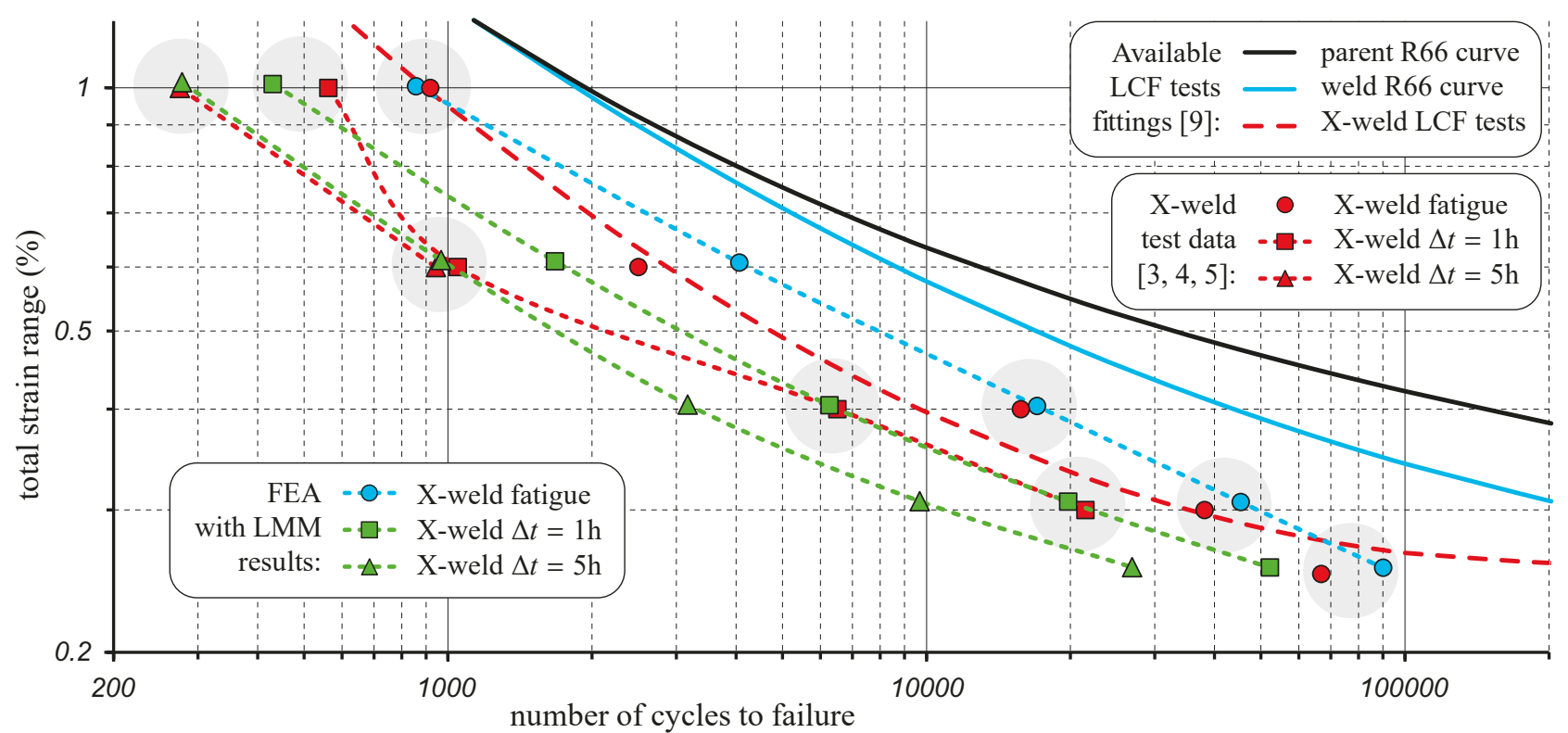

Figure 8: Results of creep-fatigue evaluation procedure in application to cruciform weldment and comparison with experimental data [3, 4, 5]
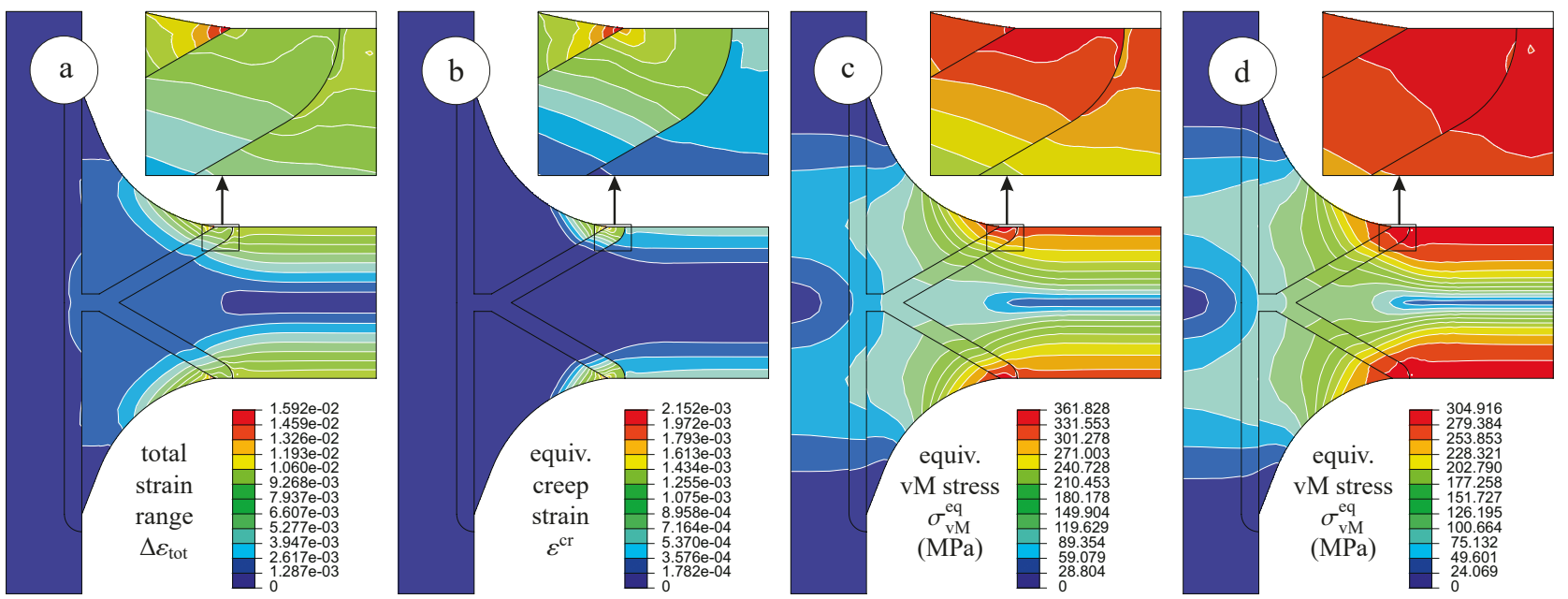

Figure 9: Contour plots of LMM results corresponding to $\Delta \varepsilon_{\text {tot }}=1 \%$ on the outer fiber of plate and $\Delta t=5$ hours of dwell period: a) total strain range $\Delta \varepsilon_{\text {tot }}$; b) equivalent creep strain $\varepsilon^{\mathrm{cr}}$; c) equivalent von Mises stress $\varepsilon_{\mathrm{vM}}^{\mathrm{eq}}$ at the beginning of dwell; d) equivalent von Mises stress $\varepsilon_{\mathrm{vM}}^{\mathrm{eq}}$ at the end of dwell 
Table 6: Summary of cycles to failure $N^{\star}$ obtained with LMM for the ranges of normalised bending moments $\tilde{M}$ and dwell periods $\Delta t$

\begin{tabular}{c|lllllllll}
\hline \hline \multirow{2}{*}{$\tilde{M}$} & \multicolumn{10}{|c}{ duration of dwell $\Delta t$, hour } \\
\cline { 2 - 10 } & 0 & 0.5 & 1 & 2 & 5 & 10 & 100 & 1000 & 10000 \\
\hline 1.4705 & 857 & 500 & 430 & 362 & 278 & 223 & 95 & 33 & 8 \\
1.1538 & 4062 & 2037 & 1673 & 1339 & 967 & 746 & 307 & 122 & 42 \\
0.9255 & 17025 & 7963 & 6270 & 4756 & 3168 & 2294 & 799 & 308 & 121 \\
0.7774 & 45374 & 24952 & 19776 & 14931 & 9679 & 6755 & 1963 & 635 & 230 \\
0.691 & 90056 & 63964 & 52221 & 40511 & 26901 & 18869 & 5116 & 1415 & 434 \\
\hline \hline
\end{tabular}

where the fitting parameters dependent on dwell period $\Delta t$ are

$$
\begin{aligned}
& a(\Delta t)=a_{1} \log (\Delta t+1)+a_{2} \quad \text { and } \\
& b(\Delta t)=b_{1} \log (\Delta t+1)+b_{2},
\end{aligned}
$$

and independent fitting parameters have the following values: $a_{1}=-0.4921, a_{2}=3.708929, b_{1}=0.0255, b_{2}=0.754959$.

Having defined the number of cycles to failure $N^{\star}$ by Eq. (32), the residual service life in years is therefore dependent on the duration of 1 cycle, which consists of dwell period $\Delta t$ and relatively short time of deformation as follows:

$$
L^{\star}=N^{\star}\left[\frac{\Delta t}{365 \cdot 24}+\frac{2 \Delta \varepsilon_{\text {tot }}(\tilde{M})}{\dot{\varepsilon}(365 \cdot 24 \cdot 60 \cdot 60)}\right]
$$

where the total strain range as a function of the normalised moment $\Delta \varepsilon_{\text {tot }}(\tilde{M})$ has been formulated fitting the LMM results from Table 4 and has a form similar to the R-O model (3):

$$
\Delta \varepsilon_{\text {tot }}(\tilde{M})=p_{1} \tilde{M}+p_{2} \tilde{M}^{p_{3}} .
$$

In notations (34) and (35) $p_{1}=0.2817, p_{2}=0.17649$ and $p_{3}=3.11051$ are the fitting parameters, and $\dot{\varepsilon}=0.03 \% / \mathrm{s}$ is a strain rate according to experimental conditions $[3,4,5]$.

The engineering parameters $N^{\star}$ and $L^{\star}$ characterising creepfatigue durability of the cruciform weldment have the key importance for design applications. For ease of use, both parameters $N^{\star}$ and $L^{\star}$ determined by Eqs (32) and (34) respectively can be represented in the form of a design contour plot, shown in Fig. 10. The contour lines (dashed for $N^{\star}$ and solid for $L^{\star}$ ) allows a design engineer to define approximately and rapidly the level of mechanical loading $\tilde{M}$ acceptable for the required service life and assumed average value of dwell period $\Delta t$. A definite value of $\tilde{M}$ corresponding to required values of $N^{\star}, L^{\star}$ and $\Delta t$ or a definite value of $\Delta t$ corresponding to required values of $N^{\star}, L^{\star}$ and $\tilde{M}$ could be estimated by the numerical solution of Eqs (34) and (35).

According to the classification given in R5 Volume 2/3 [11], the cruciform weldment belongs to the Type 2, which generally includes full penetration T-butt or fillet weldments transverse to the main loading direction, refer to $[9,31]$. Weldments are considered to be composed of parent material and the difference in behaviour of the weldment compared to the parent material is taken into account by using a Fatigue Strength Reduction Factor (FSRF). The FSRF is determined experimentally by comparing the fatigue failure data of the welded specimen with the fatigue curve derived from tests on the parent plate material. Since cruciform weldment specimens were dressed by light grinding [3] and made of austenitic steel, the geometry configuration illustrated in Fig. 1 has the FSRFs of 1.5 and 2.0 corresponding to mean and lower bound values recommended in R5 Volume 2/3 [11]. Bretherton et al. $[3,4,5]$ have defined the maximum experimental FSRF as 1.9 for this joint type. The application of thickness correction in [9] provided the FSRF of 1.564. Ponter and Chen [10] have defined the FSRF of 1.3 through application of the LMM. The actual ratio between the optimal fits of fatigue endurance curves by Eq. (5) for parent plate and dressed cruciform weldment in [9] gives the maximum FSRF of 1.664.

All this variety of the FSRFs is representative of the reduction in fatigue endurance caused by the local strain range $\varepsilon_{\text {tot }}$ enhancement in the weldment region due to the material discontinuity and geometric strain concentration effects. The above listed values do not take into account the influence of the dwell $\Delta t$ duration and, therefore, creep on fatigue endurance reduction. This limitation is eliminated by the application of the proposed analytic assessment model (32) for variable values of dwell period $\Delta t$ to the estimation of FSRFs. For this purpose Eq. (32) should be transformed using Eq. (35) into the conventional form for the description of S-N diagrams similar to Eqs (5) or (7):

$$
\Delta \varepsilon_{\text {tot }}=p_{1}\left(\frac{a(\Delta t)}{\log \left(N^{\star}\right)}\right)^{1 / b(\Delta t)}+p_{2}\left(\frac{a(\Delta t)}{\log \left(N^{\star}\right)}\right)^{p_{3} / b(\Delta t)},
$$

where the parameters $a(\Delta t)$ and $b(\Delta t)$ are defined by Eqs (33).

Thus, the FSRFs, appropriate to particular dwell periods $\Delta t$ and equal values of number of cycles to failure $N^{\star}$, are defined by the relation between the $\mathrm{S}-\mathrm{N}$ diagram corresponding to fatigue failures of parent material plate and $\mathrm{S}-\mathrm{N}$ diagrams for cruciform weldment presented by Eq. (36):

$$
\mathrm{FSRF}=\Delta \varepsilon_{\text {tot }}^{\text {parent }}\left(N^{\star}\right) / \Delta \varepsilon_{\text {tot }}^{\mathrm{x}-\text { weld }}\left(N^{\star}, \Delta t\right),
$$

where the S-N diagram for parent material plate is defined by Eq. (5) with the following polynomial coefficients referring to [9]: $m_{0}=2.2274, m_{1}=-0.94691$ and $m_{2}=0.085943$. The total strain range $\Delta \varepsilon_{\text {tot }}$ in the parent material remote from the weldment, which is required to calculate the FSRF in Eq. (37) is defined by the design limits $\tilde{M} \in[0.5 \ldots 1.5512]$ of the weldment and the mathematical lower bound of the S-N diagram for parent material plate. The lower bound for $N^{\star}$ is defined as the derivative of Eq. (5) with above listed polynomial coefficients: $\log \left(N_{\max }^{\star}\right)=m_{1} /\left(2 m_{2}\right)=5.5$. Thus, for each $\Delta t$ the FSRF is defined within the following limits: $N^{\star} \in$ [322806...1834], $\tilde{M} \in[0.9474 \ldots 1.5512]$ and $\Delta \varepsilon_{\text {tot }}^{\text {parent }} \in[0.416 \ldots 1.1285] \%$. 


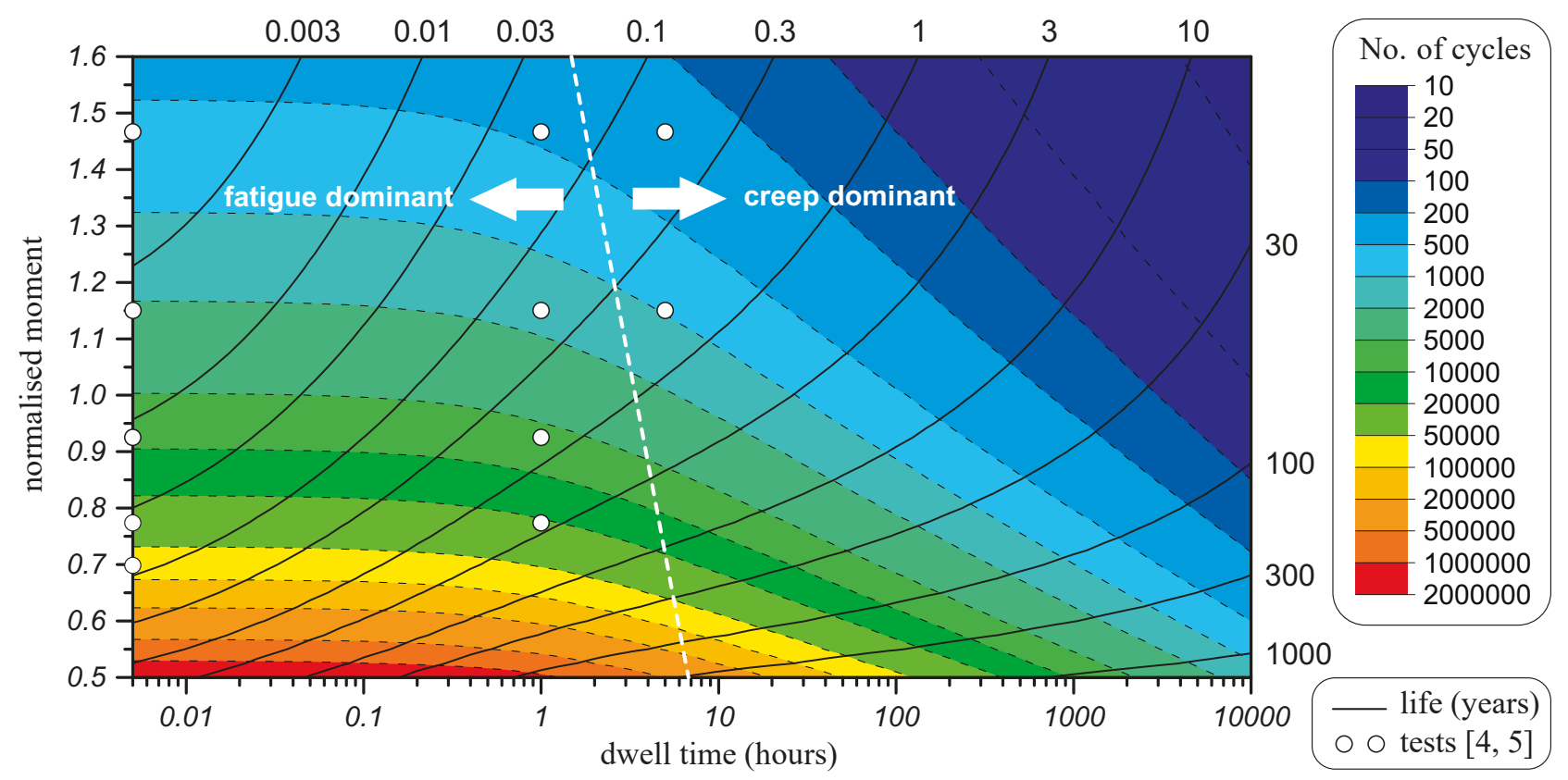

Figure 10: Design contour plot for creep-fatigue durability of cruciform weldment based on extrapolation of cycles to failure $N^{\star}$ and residual service life $L^{\star}$

The resultant dependence of FSRFs on duration of dwell $\Delta t$ is illustrated in Fig. 11, where minimum, maximum and average values are derived within the defined limits for $N^{\star}, \tilde{M}$ and $\Delta \varepsilon_{\text {tot }}^{\text {parent }}$. Figure 11 shows significant enhancement of FSRF for dwells $\Delta t>1$ hour caused by creep, which is important for design applications. For pure fatigue conditions $\mathrm{FSRF}_{\min }=1.69$, $\mathrm{FSRF}_{\max }=2.06$ and average $\overline{\mathrm{FSRF}}=1.77$, which are slightly greater than FSRFs reported in previous works. This conservatism is caused by the selected form of Eqs (32) and (33) having the minimum reasonable number of fitting parameters. Dependence of $\overline{\mathrm{FSRF}}$ on $\Delta t$ can be fitted as follows:

$$
\begin{aligned}
& \overline{\operatorname{FSRF}}(\Delta t)=f_{0}+f_{1} \log (\Delta t+1) \\
& +f_{2} \log (\Delta t+1)^{2}+f_{3} \log (\Delta t+1)^{3},
\end{aligned}
$$

where the fitting parameters have the following values: $f_{0}=$ $1.7685, f_{1}=0.53422, f_{2}=0.00574$ and $f_{3}=0.02509$.

\section{Conclusions}

Reverse bending tests of a cruciform weldment made from the steel AISI type $316 \mathrm{~N}(\mathrm{~L})$ considering different weld zones have been simulated using FEA with the LMM. Test conditions $[3,4,5]$ included constant temperature $550^{\circ} \mathrm{C}, 5$ variants of bending moment corresponding to 5 defined values of $\Delta \varepsilon_{\text {tot }}$ in remote parent material and 3 variants of creep-fatigue interaction: pure fatigue, 1 and 5 hours of dwell period $\Delta t$ of hold in bending. The design limits of the weldment have been defined by shakedown analysis with LMM using an EPP material model with corresponding constants. Shakedown analysis results with $\sigma_{\mathrm{y}}$ taken as $0.2 \%$ plastic strain offset indicate that normalised moment $\tilde{M}$ corresponding to 1 and $0.6 \%$ of $\Delta \varepsilon_{\text {tot }}$ shows an alternating plasticity response, and $\tilde{M}$ corresponding to $0.4,0.3$ and $0.25 \%$ of $\Delta \varepsilon_{\text {tot }}$ shows a shakedown response. Therefore, test loading conditions in Table 4 capture good enough the range of design limits $\tilde{M} \in[0.5 \ldots 1.5512]$. The series of creep-fatigue FE-analyses have been implemented with the LMM using:

- R-O material model and corresponding constants to describe plastic strains under saturated cyclic conditions;

- power-law model in "time hardening" form and corresponding constants to describe creep strains during primary creep stage.

The amount of damage per cycle caused by creep-fatigue interaction is estimated using:

- experimentally defined relations (5) and (7) for number of cycles to fatigue failure $N^{*}$ dependent on numerically defined total strain range $\Delta \varepsilon_{\text {tot }}$ for the fatigue damage $\omega_{\mathrm{f}}$;

- experimentally defined relation (11) for time to creep rupture $t^{*}$ dependent on the average stress $\bar{\sigma}$ during dwell period $\Delta t$ for the creep damage $\omega_{\text {cr }}$;

- $\bar{\sigma}$ is defined as a mean value (19) of the analytical function (17) for stress during relaxation which is dependent on elastic follow-up factor $Z$, initial stress $\sigma_{1}$ and time $\Delta t$.

The non-linear creep-fatigue interaction diagrams $(23,25,27,30)$ are used to define the total damage caused by both creep and fatigue, which cannot exceed one (22). Based upon these interactions, the number of cycles to creep-fatigue failure $N^{\star}$ is defined by Eqs $(24,26,29,31)$.

Comparison of the observed and predicted $N^{\star}$ with the proposed approach based on the LMM for 3 types of experiments shows that simulation of 9 of 11 totally available tests is very close to the line of optimal match, as shown in Fig. 12. Simulation of the other 2 experiments produces non-conservative results with an inaccuracy factor equal to 1.6 , which is favourable 
compared to the factor allowable for engineering analysis which is 2 . The results are slightly non-conservative for pure fatigue, slightly conservative for creep-fatigue with 1 hour dwell and optimal for 5 hours, as shown in in Fig. 12.

A set of numerical creep-fatigue LMM predictions, intended for design purposes, corresponding to $\Delta t \in[0 \ldots 10000]$ hours are extrapolated by the analytical functions (32) and (34) and used for contour plot of cycles to failure $N^{\star}$ and residual life $L^{\star}$ depending on $\Delta t$ and $\tilde{M}$. Comparison of the observed and predicted $N^{\star}$ with the analytical function (32) for 3 types of experiments also shows that simulation of 9 of the 11 available tests is close to the line of optimal match, as shown in Fig. 12. The difference in analytical predictions compared to LMM-based assessment is that the results for pure fatigue are relatively conservative, but are still within the factor of 2 allowed by engineering standards, as shown in in Fig. 12.

Therefore, the proposed function for FSRF depending on dwell time $\Delta t$ (38) for Type 2 Dressed weldments and shown in Fig. 11 allows to improve design techniques e.g. in R5 Procedure [11] by considering the significant influence of creep. Further research is devoted to parametric studies in order to determine the effect of weld geometry on key design parameters $N^{\star}$ and $L^{\star}$, and to describe this effect by formulating mathematical relations. This will enable to consider the effect of dwell time $\Delta t$ on the FSRF for Type 2 Undressed weldments, which have the durability influenced by "as-welded" geometry.

\section{Acknowledgements}

The authors deeply appreciate the Engineering and Physical Sciences Research Council (EPSRC) of the United Kingdom for the financial support in the frames of research grant no. EP/G038880/1, the University of Strathclyde for hosting during the course of this work, and EDF Energy for the experimental data.

\section{References}

1. Gorash, Y., Altenbach, H., Lvov, G.. Modelling of high-temperature inelastic behaviour of the austenitic steel AISI type 316 using a continuum damage mechanics approach. Journal of Strain Analysis 2012;47(4):229 243.

2. Chen, H.F., Chen, W., Ure, J.. Linear matching method on the evaluation of cyclic behaviour with creep effect. In: Proc. ASME Pressure Vessels $\mathcal{E}$ Piping Conf. (PVP2012). Toronto, Canada: ASME; 2012, July 15-19.

3. Bretherton, I., Knowles, G., Slater, I.J., Yellowlees, S.F.. The fatigue and creep-fatigue behaviour of $26 \mathrm{~mm}$ thick type $316 \mathrm{~L}(\mathrm{~N})$ welded cruciform joints at $550^{\circ} \mathrm{C}$ : An interim report. Report for Nuclear Electric Ltd no. R/NE/432; AEA Technology plc; Warrington, UK; 1998.

4. Bretherton, I., Knowles, G., Bate, S.K.. PC/AGR/5087: The fatigue and creep-fatigue behaviour of welded cruciform joints: A second interim report. Report for British Energy Generation Ltd no. AEAT-3406; AEA Technology plc; Warrington, UK; 1999.

5. Bretherton, I., Knowles, G., Hayes, J.-P., , Bate, S.K., Austin, C.J.. PC/AGR/5087: Final report on the fatigue and creep-fatigue behaviour of welded cruciform joints. Report for British Energy Generation Ltd no. RJCB/RD01186/R01; Serco Assurance; Warrington, UK; 2004.

6. Bretherton, I., Budden, P.J.. Assessment of creep-fatigue endurance of large cruciform weldments. In: Trans. 15th Int. Conf. on Structural Mechanics in Reactor Technology; SMiRT15 - F05/2. Seoul, Korea: IASMiRT; 1999, p. 185-192.
7. Ainsworth, R.A., Budden, P.J., Dean, D.W., O’Donnell, M.P., Tipping, D.J., Goodall, I.W., et al. Creep-fatigue crack initiation assessment procedures. In: Trans. 16th Int. Conf. on Structural Mechanics in Reactor Technology; SMiRT16 - F01/1742. Washington, DC, USA: IASMiRT; 2001, p. 1-12.

8. Ainsworth, R.A.. R5 procedures for assessing structural integrity of components under creep and creep-fatigue conditions. International Materials Reviews 2006;51(2):107-126.

9. Bate, S.K., Hayes, J.-P., , Hooton, D.G., Smith, N.G.. Further analyses to validate the R5 volume $2 / 3$ procedure for the assessment of austenitic weldments. Report for British Energy Generation Ltd no. SA/EIG/11890/R002; Serco Assurance; Warrington, UK; 2005.

10. Ponter, A.R.S., Chen, H.F.. Modeling of the behavior of a welded joint subjected to reverse bending moment at high temperature. Journal of Pressure Vessel Technology 2007;129(2):254-261.

11. Ainsworth, R.A., editor. R5: An Assessment Procedure for the High Temperature Response of Structures. Procedure R5: Issue 3. British Energy Generation Ltd, Gloucester, UK; 2003.

12. Nguyen-Tajan, T.M.L., Pommier, B., Maitournam, H., Houari, M., Verger, L., Du, Z.Z., et al. Determination of the stabilized response of a structure undergoing cyclic thermal-mechanical loads by a direct cyclic method. In: Proc. 16th Annual ABAQUS Users' Conference. Munich, Germany; 2003, Dassault Systèmes Simulia Corp.

13. ABAQUS Analysis User's Manual. Dassault Systèmes Simulia Corp.; Version 6.10 ed.; 2010.

14. Ponter, A.R.S., Chen, H.F.. A minimum theorem for cyclic load in excess of shakedown, with application to the evaluation of a ratchet limit. European Journal of Mechanics - A/Solids 2001;20(4):539-553.

15. Chen, H.F., Ponter, A.R.S.. A method for the evaluation of a ratchet limit and the amplitude of plastic strain for bodies subjected to cyclic loading. European Journal of Mechanics - A/Solids 2001;20(4):555-571.

16. Chen, H.F.. Lower and upper bound shakedown analysis of structures with temperature-dependent yield stress. Journal of Pressure Vessel Technology 2010;132(1):011202:1-8.

17. Chen, H.F., Ponter, A.R.S.. A direct method on the evaluation of ratchet limit. Journal of Pressure Vessel Technology 2010;132(4):041202:1-8.

18. Chen, H.F., Ponter, A.R.S.. Linear matching method on the evaluation of plastic and creep behaviours for bodies subjected to cyclic thermal and mechanical loading. International Journal for Numerical Methods in Engineering 2006;68(1):13-32.

19. Tipping, D.J.. The Linear Matching Method: A Guide to the ABAQUS User Subroutines. Generic Report no. E/REP/BBGB/0017/GEN/07; Central Engineering Support; British Energy Generation Ltd, Gloucester, UK; 2008.

20. Bree, J.. Elastic-plastic behaviour of thin tubes subjected to internal pressure and intermittent high-heat fluxes with application to fast-nuclearreactor fuel elements. Journal of Strain Analysis 1967;2(3):226-238.

21. Boyle, J.T., Spence, J.. Stress Analysis for Creep. London: ButterworthHeinemann; 1983.

22. Data sheets on the elevated-temperature properties for base metals, weld metals and welded joints of $18 \mathrm{Cr}-12 \mathrm{Ni}-\mathrm{Mo}$-middle $\mathrm{N}-$ low $\mathrm{C}$ hot rolled stainless steel plates (SUS 316-HP). NIMS Creep Data Sheet No. 45A; National Institute for Materials Science; Tsukuba, Japan; 2005.

23. Wada, Y., Aoto, K., Ueno, F.. Creep-fatigue evaluation method for type 304 and 316FR SS. In: Creep-fatigue damage rules for advanced fast reactor design. Vienna, Austria: IAEA; 1997, p. 75-86.

24. Wada, Y., Aoto, K.. Creep-fatigue evaluation method for modified $9 \mathrm{Cr}$ 1Mo steel. In: Creep-fatigue damage rules for advanced fast reactor design. Vienna, Austria: IAEA; 1997, p. 171-178.

25. Wada, Y., Asayama, T., Hasebe, S., Kasahara, N.. Creep-fatigue evaluation on butt welded joints of type 304 SS. In: Creep-fatigue damage rules for advanced fast reactor design. Vienna, Austria: IAEA; 1997, p. 191-200.

26. Fan, Z., Smith, D.J., Chen, X., Spindler, M.W.. Creep-fatigue lives prediction and sensitivity study of $316 \mathrm{H}$ at $550^{\circ} \mathrm{C}$. Acta Metallurgica Sinica 2011;24(2):132-140.

27. Skelton, R.P., Gandy, D.. Creep-fatigue damage accumulation and interaction diagram based on metallographic interpretation of mechanisms. Materials at High Temperatures 2008;25(1):27-54.

28. Picker, C.. UK development of a strain based creep-fatigue assessment procedure for fast reactor design. In: Creep-fatigue damage rules for 


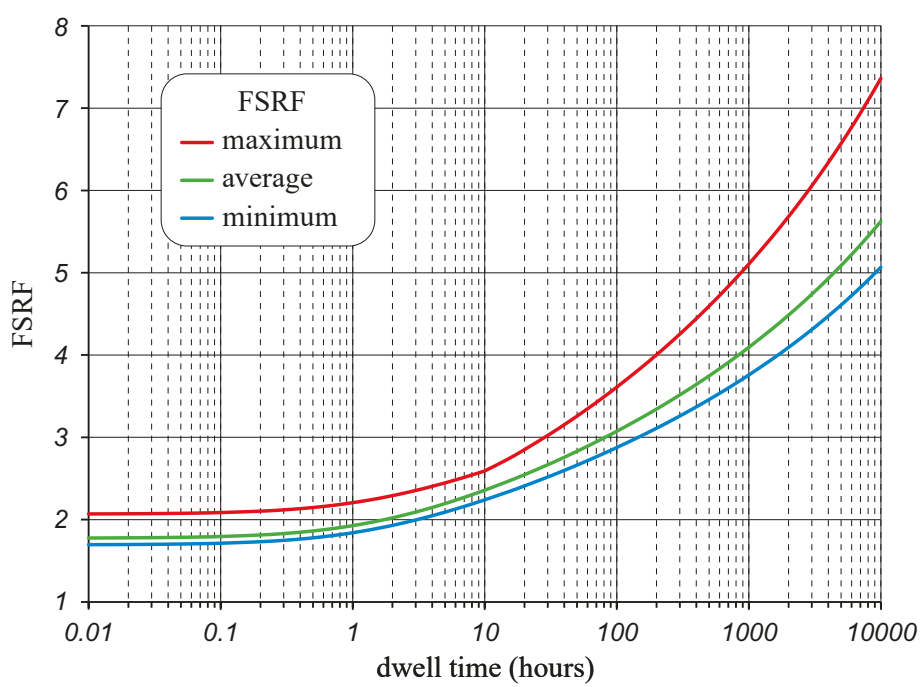

Figure 11: Dependence of FSRF on duration of dwell period $\Delta t$

advanced fast reactor design. Vienna, Austria: IAEA; 1997, p. 131-169.

29. Khazhinskii, G.M.. Procedure for structural design for long-term cyclic strength. Chemical and Petroleum Engineering 2009;45(11-12):725-732.

30. Spindler, M.W.. Improved methods for the calculation of creep damage. Generic Report no. E/REP/BBGB/0016/GEN/07; Central Engineering Support; British Energy Generation Ltd, Gloucester, UK; 2009.

31. Dean, D.W.. Recent developments in the R5 procedures for assessing the high temperature response of structures. Materials at High Temperatures 2011;28(2):95-102.

\section{Nomenclature}

\section{Abbreviations}

CDM Continuum damage mechanics

EPP Elastic-perfectly-plastic

FEA Finite Element Analysis

FSRF Fatigue strength reduction factor

HAZ Heat-affected zone

LCF Low-cycle fatigue

LMFBR Liquid metal fast breeder reactor

LMM Linear Matching Method

MMA Manual Metal Arc

R-O Ramberg-Osgood

\section{Variables, Constants}

$\sigma$

$\Delta \sigma \quad$ stress range

$\bar{\sigma} \quad$ average stress

$\varepsilon \quad$ strain

$\dot{\varepsilon} \quad$ strain rate

$\Delta \varepsilon \quad$ strain range

$\omega \quad$ damage parameter

$t \quad$ time

$\Delta t \quad$ dwell period

$E \quad$ Young's (elasticity) modulus

$\bar{E} \quad$ effective elastic modulus

$\mu \quad$ Poisson's ratio

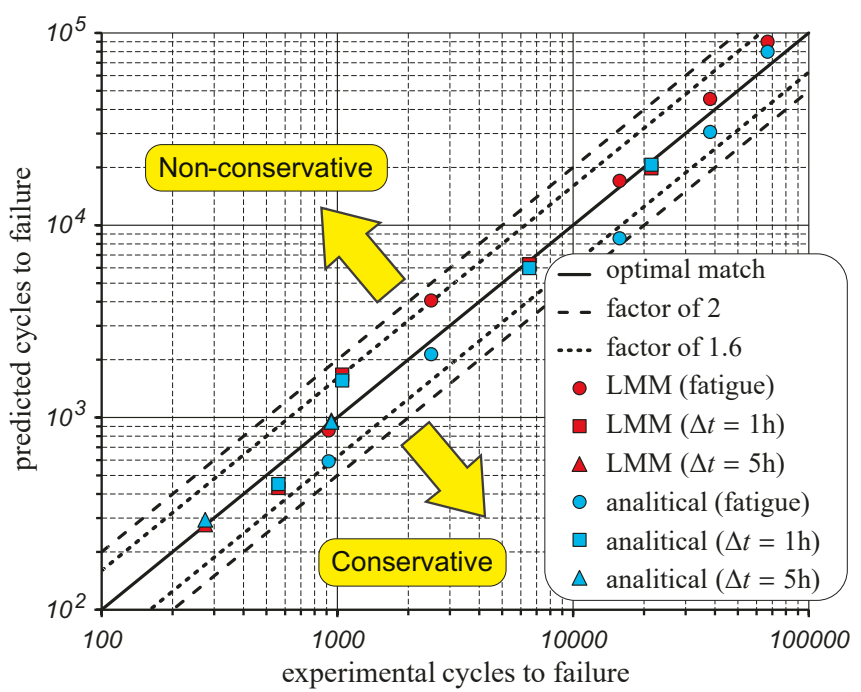

Figure 12: Comparison of the observed and predicted cycles to failure
$N$

$L$

$A, n, m$

Z

$B, k$

$c, f$

$u$

M

$\tilde{M}$

$\Delta M$

$\bar{M}$

$P$

$I_{X}$

$a, b$

$\sigma_{\mathrm{y}}$

$B, \beta$

$m_{0}, m_{1}, m_{2}, m_{3}$

$a_{1}, a_{2}, b_{1}, b_{2}$

$p_{1}, p_{2}, p_{3}$

$f_{0}, f_{1}, f_{2}, f_{3}$ number of cycles

residual life

primary creep material constants

elastic follow-up factor

creep rupture material constants

intersection on damage diagram

exponent in power-law damage diagram

bending moment

normalised moment

moment range

moment amplitude

normal pressure

area moment of inertia

width and thickness of plate

yield stress

R-O model constants

coefficients for LCF S-N curves

fitting parameters for $N^{\star}$

fitting parameters for $\Delta \varepsilon_{\text {tot }}$

fitting parameters for FSRF

\section{Subscripts, Superscripts}

cr creep

f fatigue

el elastic

pl plastic

* $\quad$ corresponding to pure fatigue

* corresponding to creep-fatigue

rat ratchet

vM von Mises

eq equivalent

tot total

var variable

const constant

lim corresponding to limit load

sh corresponding to shakedown limit 